\title{
Tryptophan metabolism in alcoholism
}

\author{
Abdulla A.-B. Badawy \\ Cardiff and Vale NHS Trust, Biomedical Research Laboratory, Whitchurch Hospital, \\ Cardiff CF14 7XB, UK
}

\begin{abstract}
Acute and chronic alcohol (ethanol) intake and subsequent withdrawal exert major effects on tryptophan (Trp) metabolism and disposition in human subjects and experimental animals. In rats, activity of the ratelimiting enzyme of Trp degradation, liver Trp pyrrolase (TP), is enhanced by acute, but inhibited after chronic, ethanol administration, then enhanced during withdrawal. These changes lead to alterations in brain serotonin synthesis and turnover mediated by corresponding changes in circulating Trp availability to the brain. A low brain-serotonin concentration characterizes the alcohol-preferring C57BL/6J mouse strain and many alcoholpreferring rat lines. In this mouse strain, liver TP enhancement causes the serotonin decrease. In man, acute ethanol intake inhibits brain serotonin synthesis by activating liver TP. This may explain alcohol-induced depression, aggression and loss of control in susceptible individuals. Chronic alcohol intake in dependent subjects may be associated with liver TP inhibition and a consequent enhancement of brain serotonin synthesis, whereas subsequent withdrawal may induce the opposite effects. The excitotoxic Trp metabolite quinolinate may play a role in the behavioural disturbances of the alcohol-withdrawal syndrome. Some abstinent alcoholics may have a central serotonin deficiency, which they correct by liver TP inhibition through drinking. Further studies of the Trp and serotonin metabolic status in long-term abstinence in general and in relation to personality characteristics, alcoholism typology and genetic factors in particular may yield important information which should facilitate the development of more effective screening, and preventative and therapeutic strategies in this area of mental health.
\end{abstract}

\section{Alcohol: Alcoholism: Serotonin: Tryptophan: Tryptophan pyrrolase}

\begin{abstract}
Abbreviations: 5-HIAA, 5-hydroxyindol-3-ylacetic acid; 5-HT, 5-hydroxytryptamine (serotonin); ADH, alcohol dehydrogenase; AlDH, aldehyde dehydrogenase; AWS, alcohol withdrawal syndrome; CAA, competing amino acids; CNS, central nervous system; CSF, cerebrospinal fluid; IAA, indol-3-ylacetic acid; IDO, indoleamine 2,3-dioxygenase; IPA, indol-3-ylpyruvic acid; MAO, monoamine oxidase; MEOS, microsomal ethanol-oxidising system; MNA, $\mathrm{N}^{1}$-methylnicotinamide; NEFA, non-esterified fatty acids; NMDA, $N$-methyl- $D$-aspartate; TP, tryptophan pyrrolase; Trp, $L$-tryptophan.
\end{abstract}

Corresponding author: Dr A. A.-B. Badawy, fax +44 292069 2644, email abdulla.badawy@cdffcomtr.wales.nhs.uk 


\section{Introduction}

The essential amino acid $L$-tryptophan (Trp) has been extensively studied in relation to alcohol (ethanol) and alcoholism because it is the precursor of the indolylamine serotonin (5-hydroxytryptamine; 5-HT), which controls a variety of important functions in the central nervous system (CNS), including mood. It is because of the frequent incidence of mood disturbances in alcohol-dependent patients that investigators have been preoccupied for over four decades now in studying the effects of alcohol consumption on the metabolism of 5-HT and its Trp precursor. It is only since the mid 1980s that it has become apparent that 5-HT may also control the desire to drink alcohol and that emphasis in alcohol-5-HT research has shifted from mood to alcoholconsummatory behaviour. In studying the Trp and 5-HT status in alcoholism, it is important to distinguish this status in dependent subjects in the absence of alcohol consumption (i.e. during medium- or long-term abstinence) from the pharmacological effects of acute and chronic consumption and subsequent withdrawal. In the present review, therefore, detailed and separate accounts of the 5-HT and Trp metabolic status in alcoholism and in relation to alcohol consumption will be given. As this is primarily a review of metabolism, no attempt will be made here to describe aspects of 5-HT receptor physiology and function or their possible modulation by alcohol. The results of the controversial studies performed in this area have already been reviewed by LeMarquand et al. $(1994 a, b)$. It may be useful to begin with a brief account of the metabolism of ethanol.

\section{Ethanol metabolism}

Over $95 \%$ of ingested ethanol is metabolized, mainly in the liver and to a much lesser extent the gastrointestinal tract, with the remaining $5 \%$ being excreted unchanged in breath, urine and sweat. Apart from via the minor glucuronidation, other conjugation and esterification pathways, and oxidation to acetaldehyde by catalase, ethanol is metabolized mainly by the quantitatively most important enzymes alcohol dehydrogenase (ADH; EC 1.1.1.1) and the microsomal ethanol-oxidizing system (MEOS), and, in particular, the cytochrome $P$-450 IIE1 isoform. Much of the basic information on these pathways is as valid now as when reviewed in the 1970s (for example, see Hawkins \& Kalant, 1972; Badawy, 1978).

The oxidation of ethanol by ADH, MEOS and catalase proceeds according to the following three reactions respectively:

$$
\begin{gathered}
\mathrm{C}_{2} \mathrm{H}_{5} \mathrm{OH}+\mathrm{NAD}^{+} \underset{\mathrm{ADH}_{2}}{\longrightarrow} \mathrm{CH}_{3} \mathrm{CHO}+\mathrm{NADH}+\mathrm{H}^{+}, \\
\mathrm{C}_{5} \mathrm{OH}+\mathrm{NADPH}+\mathrm{H}^{+}+\mathrm{O}_{2} \stackrel{M E O S}{\longrightarrow} \mathrm{CH}_{3} \mathrm{CHO}+\mathrm{NADP}^{+}+2 \mathrm{H}_{2} \mathrm{O}, \\
\mathrm{C}_{2} \mathrm{H}_{5} \mathrm{OH}+\mathrm{H}_{2} \mathrm{O}_{2} \longrightarrow \mathrm{CH}_{3} \mathrm{CHO}+2 \mathrm{H}_{2} \mathrm{O} .
\end{gathered}
$$

The acetaldehyde produced is then oxidized to acetate by the action of aldehyde dehydrogenase (AlDH; EC 1.2.1.3) according to the following equation:

$$
\mathrm{CH}_{3} \mathrm{CHO}+\mathrm{NAD}^{+}+\mathrm{H}_{2} \mathrm{O} \longrightarrow \mathrm{CH}_{3} \mathrm{COOH}+\mathrm{NADH}+\mathrm{H}^{+} \text {. }
$$

Finally, acetate enters the common acetate pool and is eventually oxidized to $\mathrm{CO}_{2}$ and $\mathrm{H}_{2} \mathrm{O}$, with production of energy. With an energy value of $30 \mathrm{~kJ}(7 \cdot 1 \mathrm{kcal}) / \mathrm{g}$, ethanol is a significant source of energy for the drinker, and strongly dependent subjects invariably derive a significant, if not a major, part of their energy intake from the 'empty' energy of the drug, resulting in malnutrition, vitamin deficiencies and further consequent complications. 
Developments in alcohol metabolic research in the past decade and a half have been concerned with the roles of gastric ADH in the so-called 'first-pass' metabolism of ethanol, and of cytochrome $P-450$ IIE1 in alcohol disposition and toxicity, and with the importance of genetic and ethnic differences in ADH and aldehyde dehydrogenase (AIDH) in elimination of, and sensitivity to, and indeed in dependence on, and organ damage caused by, ethanol. However, a detailed discussion of these important aspects is outside the immediate scope of the present review. As will be seen later, the decrease in the hepatic cytosolic $\mathrm{NAD}^{+}: \mathrm{NADH}$, which results from ethanol oxidation by liver $\mathrm{ADH}$, can influence the metabolism of 5-HT and its Trp precursor.

\section{Tryptophan metabolism and disposition}

In addition to its incorporation into proteins, Trp is metabolized in man and other mammals by at least four known pathways: (1) the kynurenine-nicotinic acid, (2) the 5-HT, and those involving (3) decarboxylation to tryptamine and (4) transamination to indolylpyruvate. The first of these four pathways is the quantitatively most important. For the purposes of the present review, the role of Trp in protein synthesis and its metabolic and other biological (including nutritional) effects will not be discussed here, but have been reviewed by Bender (1982). The following is a brief account of the main features of the above four pathways, especially the first two, although, for greater detail, the reader may also wish to consult the review by Bender (1982) of the biochemistry of Trp in health and disease.

\section{The hepatic kynurenine-nicotinic acid pathway}

Main features of the pathway. This major pathway of Trp degradation accounts for at least $90 \%$ of total free Trp breakdown under normal conditions. It is also of major functional significance, because it produces a number of physiologically active intermediates (Fig. 1). The ratelimiting enzyme of the pathway, tryptophan 2,3-dioxygenase (EC 1.13.11.11) or Trp pyrrolase (TP), controls the overall rate of Trp degradation and hence, not only the rate of production of physiologically active intermediates, but also, at the primary level of control, Trp availability in the liver and elsewhere. The following are brief accounts of the functions and regulation of TP, reviews of which have been published (Badawy, 1977, 1984).

Functions of tryptophan pyrrolase. The functions of TP are those resulting from: (1) utilization of haem; (2) flux of Trp through the hepatic kynurenine-nicotinic acid pathway; (3) influence of the enzyme on hepatic and extrahepatic Trp availability for Trp-dependent functions.

Because TP is a haemoprotein, it utilizes the free or readily-exchangeable pool of haem thought to mediate the feedback regulation of the mammalian haem-biosynthetic pathway, exerted at the level of the rate-limiting enzyme, 5-aminolaevulinate synthase (Badawy, 1979). Thus many experiments conducted under conditions involving changes in the synthesis and/or degradation of hepatic haem have shown rat liver TP to respond exquisitely to these changes in terms of altered haem saturation of the enzyme (for example, see Badawy, 1979; Badawy et al. 1986 and references cited in both; Drummond et al. 1987; Cebrian et al. 1988; Siddiqui et al. 1988; Kaliman \& Manandhar, 1990). The main conclusions from these studies are that: (1) TP from rat liver can be used as a sensitive marker of changes in intracellular haem availability; (2) 
Tryptophan<smiles>NC(Cc1c[nH]c2ccccc12)C(=O)O</smiles>

\section{Tryptophan dioxygenase}

and formylkynurenine formamidase

Kynurenine<smiles>Nc1ccccc1C(=O)CC(N)C(=O)O</smiles><smiles>COC(=O)C(N)CC(=O)c1cccc(O)c1N</smiles>

3-Hydroxykynurenine

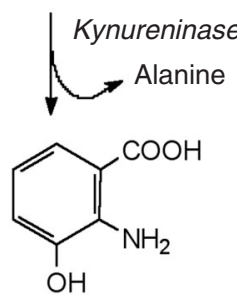

3-Hydroxyanthranilic acid

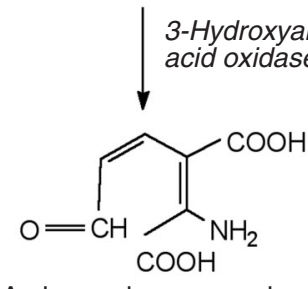

Amino-carboxymuconic semialdehyde
Kynurenine aminotransferase

$\overrightarrow{K y n u r e n i n e ~ a m i n o t r a n s f e r a s e}$<smiles>O=C(O)c1cc(O)c2ccccc2n1</smiles>

Kynurenic acid

Xanthurenic acid<smiles>O=C(O)c1cc(O)c2cccc(O)c2n1</smiles> 
the haem used by TP is the 'regulatory' pool; (3) the size of the haem pool in the hepatic cytosol is approximately $10^{-7} \mathrm{M}$; (4) the utilization of haem by TP is not a passive expression of, but can influence, its availability for feedback regulation of haem biosynthesis. TP may therefore be an important regulator of mammalian liver haem biosynthesis.

As TP controls the flux of Trp through the hepatic kynurenine-nicotinic acid pathway, it must be assumed to exert an important role in determining the rate of synthesis of the biologically active and other intermediates of the pathway. Biologically important intermediates are the convulsant kynurenine, the neurotoxic and powerful endogenous (if indirect-acting, via glutamate) agonist of the $N$-methyl- $D$-aspartate (NMDA)-type of glutamate receptors quinolinic acid, the NMDA receptor antagonist and cytoprotective kynurenic acid (Stone, 1993), the vitamin-like substance nicotinic acid, the important redox cofactors $\mathrm{NAD}^{+}\left(\mathrm{P}^{+}\right)$and their reduced forms, and xanthurenic acid, which can inactivate insulin (Kotake \& Murakami, 1971) and has been identified as the malaria gametocyte-activating agent (Billker et al. 1998). Quinolinic acid can also inhibit gluconeogenesis (for references and discussion, see Bender, 1982). The potential role(s) of some of these intermediates in alcohol dependence and modulation of their metabolism by alcohol intake will be considered later (p. 141).

That TP controls the flux of Trp through the hepatic kynurenine-nicotinic acid pathway is an undisputed fact (Young \& Sourkes, 1975; Smith et al. 1980; Salter et al. 1986), and it has been estimated by Young \& Sourkes (1975) that the liver of a rat degrades the whole of its free (non-protein-incorporated) Trp through the action of TP every $7 \mathrm{~min}$. It follows therefore that TP determines Trp availability for its various functions. As an essential amino acid, Trp is needed for protein synthesis in the liver and elsewhere. Under certain conditions, for example those involving increased levels of glucocorticoids, the resultant TP induction (see p. 127) can limit Trp availability for protein synthesis and, together with effects on other amino acids and metabolic processes, this induction leads to enhanced protein degradation and an overall negative $\mathrm{N}$ balance (Bender, 1982). Trp in the liver is involved in other important processes, for example those associated with protein synthesis (such as RNA and poly (A) polymerase activity, nuclear synthesis of DNA-like RNA, polyribosomal RNA synthesis, polysomal aggregation etc.; Sidransky et al. 1996), and possibly also stimulation of haem biosynthesis (Badawy \& Morgan, 1982). One of the most important extrahepatic functions of Trp is its use by the brain for 5-HT synthesis, as will be discussed further later (p. 130). However, in the context of the present discussion, liver TP plays a major role, at the primary level of control, in determining Trp availability in the circulation for this important cerebral function (Badawy, 1977, 1984).

Regulation of tryptophan pyrrolase. TP was one of the earliest enzymes used in developing the concept of enzyme, and hence metabolic regulation, and specifically glucocorticoid or hormonal induction of enzymes. Since the pioneering studies of the group of Knox (Knox \& Auerbach, 1955; Mehler et al. 1958), this mechanism has been developed further, and we now know that: (1) it involves de novo synthesis of new enzyme protein without a change in the rate of its degradation (Schimke et al. 1965a); (2) induction occurs at the transcriptional level (Schutz et al. 1973; DeLap \& Feigelson, 1978; Nakamura et al. 1987); (3) the net results are increased rates of protein catabolism and of gluconeogenesis (Bender, 1982); (4) induction provides protection against toxicity in many mammalian species when exposed to an excess of Trp (Badawy \& Evans, $1976 b$ and references cited therein).

Some hormones and messengers, other than glucocorticoids, can also modulate TP activity. These include insulin, glucagon, cyclic AMP, catecholamines, and sex hormones. Both glucagon and dibutyryl cyclic AMP enhance the glucocorticoid induction of TP, whereas 
insulin suppresses it (Nakamura et al. 1980). Suppression of TP induction by glucocorticoids or glucagon is also achieved by adrenaline (Noda et al. 1983), although, as will be described later (p. 132), catecholamines activate TP by a substrate-type mechanism. Large doses of oestrogens induce TP activity, almost certainly by releasing glucocorticoids (Braidman \& Rose, 1971), whereas smaller pharmacological doses (and also of progesterone) inhibit it (Bender \& Totoe, 1984; Badawy, 1988); these latter effects may explain the decrease in TP activity observed in pregnant rats (Badawy, 1988).

TP is also regulated by three additional mechanisms. Substrate activation became known shortly after hormonal induction (Greengard \& Feigelson, 1961) and its most distinguishing features are the stabilization of the enzyme by its Trp substrate (Schimke et al. 1965a,b) and the increased haem saturation of the enzyme (hence the term activation), which occurs both early and during the entire activation time-course (Greengard \& Feigelson, 1961; Badawy \& Evans, $1975 b$ ). This activation led to the identification of the third mechanism of TP regulation, namely cofactor activation. Here, TP activation is not associated with increased synthesis or stabilization of the enzyme, but, like substrate activation, involves increased haem saturation (Badawy \& Evans, 1975b). In fact, haem forms a common link between the substrate and cofactor mechanisms. Thus, because Trp does not enhance TP synthesis, the ability of translational inhibitors, such as cycloheximide, to block the Trp effect, an inexplicable observation known for some time, was explained (Badawy \& Evans, 1975b) on the basis of Trp enhancing haem biosynthesis. Recently, Ren \& Correia (2000) reported that haem may be necessary for glucocorticoid-induced TP mRNA transcription and translation, thus involving haem further in TP regulation.

The fourth mechanism of TP regulation is that of product or feedback inhibition, especially by $\mathrm{NAD}(\mathrm{P}) \mathrm{H}$. Wagner (1964) showed that a number of intermediates of the kynureninenicotinic acid pathway inhibit TP activity in vitro. However, in vivo levels of these intermediates under normal conditions are not inhibitory, except for $\mathrm{NAD}(\mathrm{P}) \mathrm{H}$, which have been shown to be allosteric inhibitors of activity of purified TP (Cho-Chung \& Pitot, 1967). Further support for this mechanism was obtained from experiments involving chronic administration to rats of glucose or nicotinamide (Badawy \& Evans, 1976a), and, as will be stated later (p. 134), this may also be the mechanism by which chronic ethanol administration inhibits liver TP activity.

\section{The kynurenine pathway in brain and other extrahepatic tissues}

Although the $L$-Trp-specific TP is confined to the liver, the less substrate-specific indoleamine 2,3-dioxygenase (IDO; EC 1.13.11.17) is present in brain and other extrahepatic human tissues (Yamazaki et al. 1985). Under basal conditions in the rat, IDO activity is much smaller than that of hepatic TP, thus suggesting that IDO plays a minor role in Trp degradation under normal physiological conditions in this species. The same is not true for the gerbil, whose lung IDO activity is greater than that of liver TP under normal basal conditions (Heyes et al. 1997). The gerbil is one of the species sensitive to Trp toxicity which possesses a lower liver TP activity, compared with the rat and other species which can metabolically handle an excess of Trp without untoward effects (Badawy \& Evans, 1976b). The relative importance of IDO and TP in human Trp degradation under normal conditions is currently unknown. Under conditions of immune activation, however, for example after viral, parasitic and other infections, in immune diseases and some neurological conditions, activity of IDO can be dramatically elevated to levels exerting a major controlling influence on total body Trp degradation (for review, see Taylor \& Feng, 1991). The principal effector of IDO is interferon $\gamma$ (Pfefferkorn et al. 1986; 
Taylor \& Feng, 1991), hence the strong association of its induction with immune activation (Taylor \& Feng, 1991), and the proposal that the antiproliferative effect of this cytokine could be mediated by Trp depletion (Ozaki et al. 1988). Another important feature of IDO induction is the potential cerebral synthesis of the excitotoxic Trp metabolite quinolinate, which may be responsible, at least in part, for the neurological symptoms in brain injury and other neurological conditions (Heyes, 1996 and references cited therein). The brain contains the enzymes needed for quinolinate synthesis from kynurenine, even if it does not possess all subsequent enzymes of the pathway. It is also noteworthy that, even if brain IDO is not induced, kynurenine from peripheral sources (mainly the liver) easily crosses the blood-brain barrier and is thus converted into quinolinate, and that, additionally, about $40-50 \%$ of brain quinolinate is also of peripheral origin (Heyes \& Morrison, 1997). As will be discussed later (p. 141), quinolinate may also have a potential role in the alcohol withdrawal syndrome (AWS).

\section{The serotonin pathway}

Main features of the pathway. This minor pathway of Trp degradation has a major functional significance in the CNS and elsewhere, as it results in production of two physiologically important compounds, 5-HT and (in the pineal gland and to a small extent the retina) melatonin. Fig. 2 illustrates the main features of the 5-HT pathway. 5-HT is synthesized from Trp by hydroxylation to 5-hydroxytryptophan, then decarboxylation of the latter to 5-HT. Although decarboxylation could become rate-limiting under certain conditions (nutritional and/or functional pyridoxine deficiency; Bender, 1982), the hydroxylation step is generally more important. 5-HT is then metabolized in two ways. First, it is oxidatively deaminated by the action of monoamine oxidase (MAO), in particular the A isoform, to 5-hydroxyindol-3-ylacetaldehyde. This aldehyde is then converted under normal conditions mainly to 5-hydroxyindol-3-ylacetic acid (5-HIAA), the major 5-HT oxidation product and urinary metabolite, by the action of AlDH, but to a much lesser extent to 5-hydroxytryptophol through a minor reductive pathway catalysed by an aldehyde reductase. As will be shown below, acute alcohol intake promotes this minor reductive, at the expense of the above major oxidative, pathway.

The other route of 5-HT metabolism involves melatonin production in the pineal gland, by a two-step process: $N$-acetylation of 5-HT to $N$-acetyl 5 -HT by the action of 5-HT $N$-acetyltransferase, followed by $o$-methylation of this intermediate to melatonin (5-methoxy- $N$-acetyl 5 -HT) by the action of hydroxyindole-o-methyltransferase. Melatonin regulates many body functions, notably reproduction and the circadian rhythm, and has more recently been shown to influence oxygen metabolism as an electron donor, free radical scavenger and antioxidant (for review, see Reiter, 1996). These latter effects may explain melatonin's protection against ethanol-induced lipid peroxidation (El-Sokkary et al. 1999), which is believed to be a critical factor in alcohol-induced organ damage.

5-HT is also converted to complex condensation products by non-enzymic reaction with acetaldehyde or biogenic aldehydes, including its own aldehyde 5-hydroxyindol-3-ylacetaldehyde, to form compounds of the $\beta$-carboline type, such as norharman $(\beta$-carboline; $9-\mathrm{H}$ pyrido(3,4-b)indole) and harman (1-methyl- $\beta$-carboline; 1-methyl-9H-pyrido(3,4-b)indole). These compounds possess interesting pharmacological properties, including anxiogenesis, increased alcohol consumption, inhibition of MAO activity, elevation of brain 5-HT levels, and modulation of neuronal function (for references, see Spies et al. 1995; Wodarz et al. 1996). However, their possible involvement in the behavioural and other effects of alcohol, particularly in the CNS, has not been established, almost certainly because of their low CNS levels. 


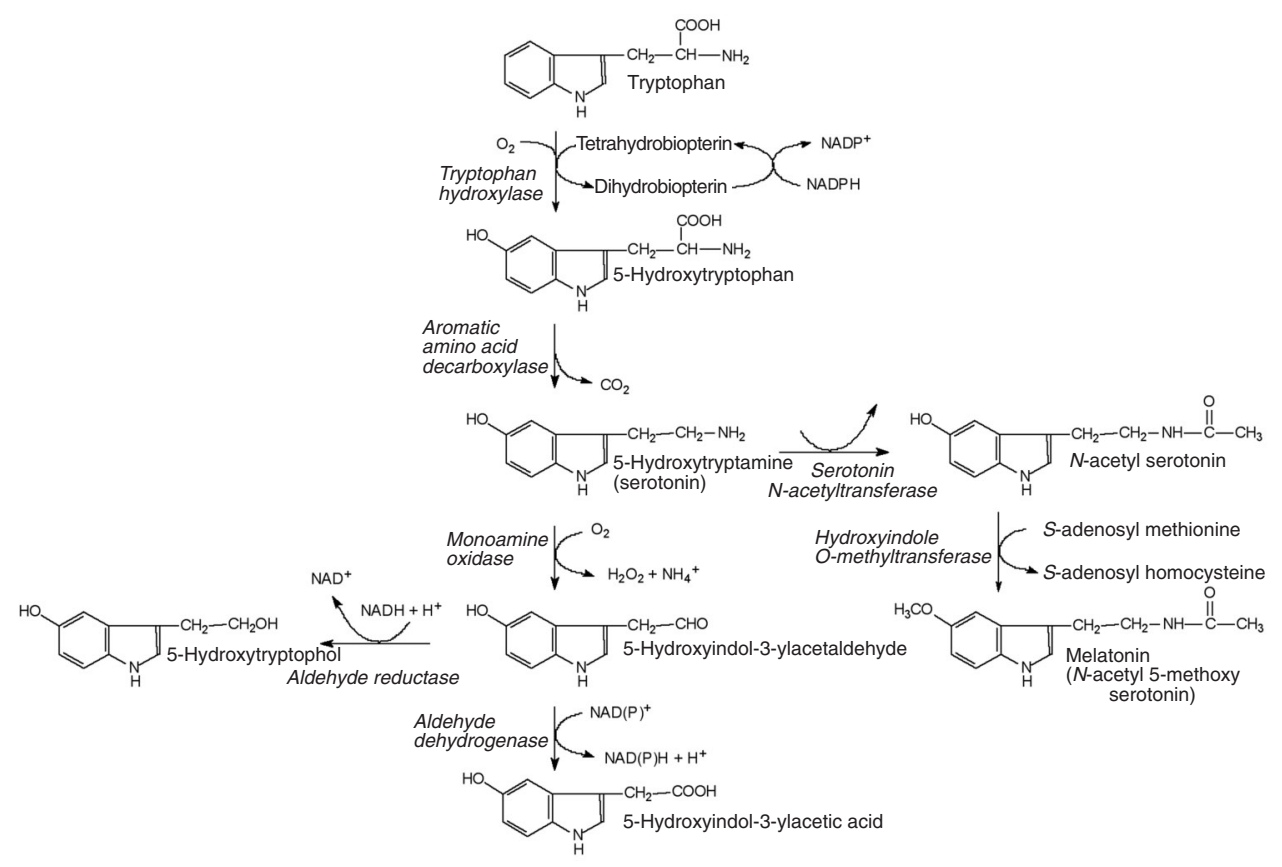

Fig. 2. The serotonin pathway of tryptophan degradation.

Control of brain serotonin synthesis. Although Trp hydroxylase is rate-limiting for 5-HT synthesis, it has a relatively long half-life of about 2-3 d (Meek \& Neff, 1972) and exists unsaturated with its Trp substrate (i.e. its $K_{\mathrm{m}}$ of at least $25 \mu \mathrm{mol} / \mathrm{l}$ with the natural tetrahydrobiopterin cofactor (Gal, 1974) is higher than brain Trp concentration, which is on average 15 $\mu \mathrm{mol} / \mathrm{kg}$ ). Consequently, brain Trp concentration is an important metabolic determinant of the rate of cerebral 5-HT synthesis (Fernstrom \& Wurtman, 1971; Carlsson \& Lindqvist, 1978; Curzon, 1979). This is of course in addition to other determinants, such as the rate of firing of 5-HT neurons, the influence of other neurotransmitters on these neurons, and the state of phosphorylation of Trp hydroxylase. It follows therefore that peripheral factors influencing circulating Trp availability to the brain must play important roles in cerebral 5-HT synthesis. At the primary level, as discussed above, liver TP is the major determinant of the rate of Trp degradation and hence availability to the brain. At the secondary, but more immediate level, two other peripheral factors share the control: (1) Trp binding to circulating albumin (Curzon, 1979); (2) competition between Trp and other amino acids for entry into the brain. As regards Trp binding, only about $10 \%$ of circulating Trp exists in the free unbound state (though in equilibrium with the $90 \%$ albumin-bound fraction) and therefore available for tissue uptake. Non-esterified fatty acids (NEFA) are the physiological displacers of albumin-bound Trp (Curzon \& Knott, 1974), and it will be seen later (p. 132) that, in rats, acute ethanol administration increases Trp entry into the brain by increasing circulating NEFA concentration. Other agents increasing NEFA concentration include catecholamines, methylxanthines and clofibrate. Salicylate, other nonsteroidal anti-inflammatory agents, and many other drugs can displace Trp directly from its albumin-binding sites, and thus increase its entry into the brain. By contrast, antilipolytic agents, such as nicotinic acid and insulin, lower NEFA concentration and thus increase Trp binding. Insulin, however, causes a net increase in brain Trp concentration by decreasing the level of the above competing amino acids. Competition for Trp entry into the brain comes from 
twelve other amino acids (Oldendorf \& Szabo, 1976), of which the five most commonly measured in a simple approximation are valine, leucine, isoleucine, phenylalanine and tyrosine. Using this simple approximation, in studies with human subjects, the most accurate predictor of changes in brain Trp concentration and hence 5-HT synthesis is therefore not the concentration of circulating Trp alone, but Trp : competing amino acids (CAA).

\section{The decarboxylation and transamination pathways}

The decarboxylation and transmination pathways are also minor pathways (Fig. 3), but, like that of 5-HT, produce biologically important substances, namely tryptamine and indol-3ylpyruvic acid (IPA). Decarboxylation of Trp to tryptamine occurs in both the CNS and the periphery, and these, together with intestinal bacterial production of tryptamine and the ability of the latter to cross the blood-brain barrier, all account for the origin of brain tryptamine (Bender, 1982 and references cited therein). Tryptamine possesses a number of behavioural, physiological and pharmacological properties and has been implicated in a number of psychiatric conditions (Mousseau, 1993) and also in hepatic encephalopathy (Bengtsson, 1999). The transamination pathway leads, via an unstable intermediate, to the production of IPA, a metabolite shown to possess a variety of interesting behavioural, biochemical and pharmacological properties, including inhibition of liver TP activity, elevation of brain 5-HT and kynurenic acid levels, enhancement of melatonin turnover in the pineal gland, antioxidant and free-radical scavenging effects, antagonism of excitatory amino acid effects, anxiolytic effects, suppression of circulating glucocorticoid levels and inhibition of their damaging effects in the hippocampus (for reviews, see Politi et al. 1996, 1999). In man, IPA has been shown in volunteers and patients with sleep disturbances to be anxiolytic, to promote sleep and to enhance mood (Politi et al. 1999).

\section{Effects of alcohol on tryptophan metabolism in animals}

\section{Acute effects}

The decarboxylation and transamination pathways. The effects of ethanol on the transamination pathway are not known. The product of this pathway, IPA, however, has been shown to antagonize the depressant and behavioural effects of ethanol in mice (Lapin \& Politi, 1994). Very little work has been done on the effects of ethanol on the tryptamine pathway. The conversion of tryptamine to indol-3-ylacetic acid (IAA) in vitro is impaired by low concentrations of ethanol (Asaad et al. 1974), possibly through inhibition of MAO activity. More importantly, ethanol may inhibit tryptamine oxidation to IAA by diverting the conversion of the intermediate aldehyde to the reduction product tryptophol. This diversion will be discussed later (p. 139) in relation to the similar modulation of 5-HT oxidation by ethanol.

The hepatic kynurenine-nicotinic acid pathway. Only the effects of ethanol on the hepatic pathway have been studied, and, in particular, TP activity. Brodie et al. (1961) showed that acute ethanol administration enhances rat liver TP activity and suggested that ethanol acts by stimulating the pituitary-adrenal axis, because the enhancement was abolished by the $\alpha$ adrenoceptor blocker dibenamine. Badawy \& Evans (1972) then observed a biphasic enhancement of TP activity after intraperitoneal administration of a $4 \mathrm{~g}$ ethanol/ $\mathrm{kg}$ dose to male Wistar 

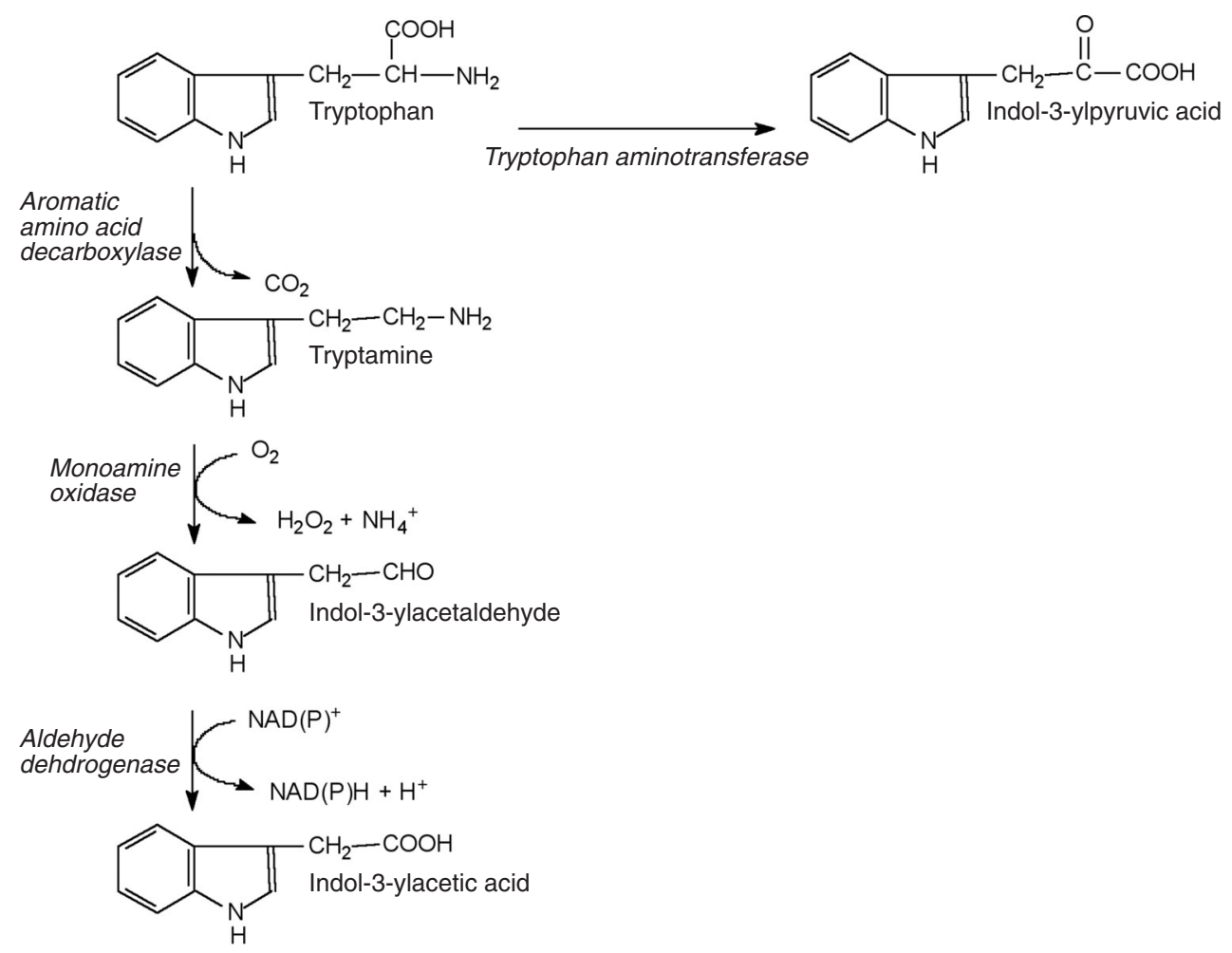

Fig. 3. The transamination and decarboxylation pathways of tryptophan degradation.

rats: (1) an initial transitory stimulation followed by a major (4-fold) enhancement. The initial increase was suggested to be due to a possible increase in NADH concentration, whereas the subsequent major enhancement was proposed to be of the cofactor-type, as it was associated with increased haem saturation of the enzyme. In the same year, Sardesai \& Provido (1972) also reported a rat liver TP enhancement by ethanol (but only by 2 -fold) and suggested its mediation by either corticosteroids or haem. Evidence that TP activation by ethanol (in the fed rat) was of the substrate-type, induced by a lipolysis-dependent NEFA-mediated release of albumin-bound Trp secondarily to release of adrenal catecholamines was subsequently obtained in this laboratory (Badawy \& Evans, 1975a, 1976c). In these two studies, we also demonstrated TP activation by intraperitoneal administration of adrenaline and noradrenaline, and also after oral ethanol administration, in contrast to the finding of no activation by this latter route by Rouach et al. (1980), who suggested that ethanol mimics the effect of Trp on TP activity only in starved rats. Rouach et al. (1980) also found that ethanol inhibited the cortisol induction of TP activity in both fed and starved rats, whereas we observed no such inhibition, but, on the contrary, an additive effect, when ethanol and cortisol were given together to fed rats (Badawy \& Evans, 1973). Stowell et al. (1983) also failed to demonstrate TP activation by ethanol in fed rats, and Mørland et al. (1985) suggested that corticosterone mediates the ethanol effect. Since then, we have performed additional experiments in both fed and starved rats (CJ Morgan and AA-B Badawy, unpublished results), which throw further light on TP activation by ethanol, suggesting that, in fed rats, activation is indeed caused by Trp, whereas that in starved animals 
is mediated by haem. No role for glucocorticoids is suggested. All the above studies were performed in rats. We (Badawy \& Evans, 1976c) also studied the ethanol effect in two mouse strains and observed TP activation in the CBA/CA, but not in the alcohol-preferring C57BL/6J, strain. In summary, enhancement of liver TP activity by ethanol is a robust observation in rats, but strain-dependent in mice. The TP enhancement in rats is expressed in terms of activation, rather than true induction, and involves stimulation of the pituitary-adrenal axis with the consequent release of adrenal catecholamines.

The serotonin pathway. Various studies have shown ethanol to increase, decrease or exert no changes in steady-state levels of 5-HT and its major metabolite 5-HIAA in whole brain and/or different regions of the brain (for references, see LeMarquand et al. 1994b). Explanations of these contradictory findings suggested by these latter authors and previously by Badawy \& Evans (1976c) include differences in species and/or strain of animal used, doses of ethanol and routes of its administration, choice of time-interval, and the use of either MAO inhibitors to measure 5-HT turnover rates, or of sucrose treatment of control rats, both of which exert effects on 5-HT metabolism which confound interpretation of the ethanol effects.

However, although available evidence strongly suggests that acute ethanol administration to rats, in general, enhances brain 5-HT synthesis, turnover and function (for references, see LeMarquand et al. 1994b), our earlier more detailed time-course study (Badawy \& Evans, 1976c) demonstrated a biphasic effect of ethanol on rat brain 5-HT synthesis and turnover; an initial enhancement followed by a later inhibition, both of which are caused by changes in circulating Trp availability to the brain leading to modulation of brain Trp concentration. Thus, the rise in brain Trp concentration causing the initial enhancement of 5-HT synthesis and turnover is due to elevation of free serum Trp concentration following displacement from albumin-binding sites by NEFA, whose serum levels are elevated secondarily to enhanced lipolysis, because of increased release of adrenal catecholamines. This increase in free serum Trp concentration also leads to an increased entry of Trp into the liver and a consequent substrate-type activation of liver TP, as discussed above. Because of this TP activation, the resulting increase in hepatic Trp degradation lowers the amino acid levels in serum (both the free fraction and the total) and hence its availability to the brain, thus resulting in a decreased entry of Trp into the brain and a consequent inhibition of brain 5-HT synthesis and turnover (Badawy \& Evans, 1976c). These opposite effects on brain 5-HT illustrate the importance of choice of the time-interval after ethanol administration. Species and strain differences are also important determinants of the acute effects of ethanol, as illustrated by the finding (Badawy \& Evans, 1976c) that ethanol inhibits brain 5-HT synthesis (at $2 \mathrm{~h}$ ) by decreasing brain Trp concentration by lowering circulating Trp availability to the brain in CBA/CA, but not in C57BL/6J, mice, effects corresponding to the early activation of liver TP only in the former mouse strain.

Acutely, ethanol also diverts 5-HT metabolism from the major oxidative, to the minor reductive, pathway. This effect has been demonstrated initially in man in urine samples and will be discussed further later (p. 138). In rats, however, interest in this effect centred on whether there is sufficient $\mathrm{ADH}$ activity in brain to induce large enough increases in brain acetaldehyde concentration and NADH : $\mathrm{NAD}^{+}$(see later; p. 139) to facilitate the above diversion. Beck et al. (1986) showed that 5-hydroxytryptophol concentration is indeed increased in two brain areas (pons medulla and diencephalon) after acute ethanol administration. Acute ethanol administration to rats has also been shown (Rommelspacher et al. 1984) to increase the brain and urine concentrations of the complex 5-HT condensation products, the $\beta$-carbolines, but the pharmacological significance of these effects remains to be assessed. 


\section{Chronic effects}

As far as can be ascertained, no studies of the effects of chronic ethanol administration to experimental animals on the decarboxylation and transamination pathways have been reported.

The hepatic kynurenine-nicotinic acid pathway. Urinary kynurenine metabolite excretion studies following acute Trp loading in alcoholic subjects, which will be described later (p. 139), led us to believe that chronic ethanol consumption may inhibit liver TP activity; an effect first demonstrated in our study with male Wistar rats (Badawy \& Evans, 1972), which also showed that subsequent withdrawal caused a rebound enhancement. We subsequently showed (Badawy \& Evans, 1973) that this TP inhibition is caused by the NADH- and NADPH-dependent allosteric mechanism proposed by Cho-Chung \& Pitot (1967), a conclusion supported subsequently by findings demonstrating increased hepatic concentrations of $\mathrm{NAD}(\mathrm{P}) \mathrm{H}$, reversal of the inhibition by addition of $\mathrm{NAD}^{+}$or $\mathrm{NADP}^{+}$in vitro or by $\mathrm{NAD}^{+}$ regeneration in vivo by acute administration of fructose, pyruvate (Badawy \& Evans, 1975a), phenazine methosulfate or methylene blue (Badawy et al. 1979), and prevention of the ethanol inhibition by chronic treatment with the ADH inhibitor pyrazole, which also prevents the chronic ethanol-induced increases in liver NAD(P)H concentration (Punjani et al. 1979). We (Badawy \& Evans, 1975a) also found that the cortisol induction of TP activity in chronically ethanol-treated rats was not impaired, thus excluding inhibition of enzyme (protein) synthesis as the mechanism of inhibition of TP activity. This mechanism was proposed by Mørland (1974), because the dexamethasone induction of TP activity in the perfused rat liver was decreased by previous chronic ethanol treatment. However, this latter finding could be explained by the ethanol-treated rats of Mørland (1974) having also been given sucrose, which inhibits both the basal TP activity (Badawy \& Evans, 1976a) and that induced by cortisol (Evans \& Badawy, 1977). Other studies (Badawy \& Evans, 1979) with the translational inhibitor cycloheximide and other agents have further disproved the idea that inhibition of liver TP activity by chronic ethanol administration is due to inhibition of enzyme (protein) synthesis.

Inhibition of rat liver TP activity by chronic ethanol administration was demonstrated in numerous, but not all, studies (for references, see LeMarquand et al. 1994b), and when ethanol was given in either drinking water (Badawy \& Evans, 1972, 1973), or a liquid diet (Mørland, 1974). However, in another study with liquid diets (Branchey \& Lieber, 1982), TP activity and urinary excretion of kynurenine (another index of TP activity) were both enhanced. However, careful examination of the Branchey \& Lieber (1982) study revealed that TP activity and urinary kynurenine were determined respectively at 3 and $10 \mathrm{~h}$ after removal of the liquid diet. Our more recent studies with the liquid diet procedure (see p. 136) revealed that TP activation during alcohol withdrawal is rapid, reaching a maximum at about $8-10 \mathrm{~h}$ after withdrawal. We therefore believe that the above conclusion by Branchey \& Lieber (1982) applies more to the effect of alcohol withdrawal, rather than of the earlier chronic treatment.

The effects of chronic ethanol administration on TP and other enzymes of the hepatic kynurenine-nicotinic acid pathway were also studied by Shibata (1990), who administered ethanol in drinking water to rats maintained on a $200 \mathrm{~g}$ casein $/ \mathrm{kg}$ diet, which also contained $230 \mathrm{~g}$ sucrose $/ \mathrm{kg}$, and showed that TP activity was little affected by the ethanol treatment. The control TP activity was, however, low $(<1 \mu \mathrm{mol}$ kynurenine formed/h per $\mathrm{g}$ of liver), which may be explained by a possible inhibition by sucrose, as discussed ealier (p. 128), which could have masked a potential ethanol effect. Shibata (1990) also found no ethanol effect on activities 
of kynureninase, nicotinamide mononucleotide adenyltransferase, NAD ${ }^{+}$synthetase and nicotinamide methyltransferase. However, activities of the two $\mathrm{N}^{1}$-methylnicotinamide (MNA) oxidases forming $\mathrm{N}^{1}$-methyl-2-pyridone-5-carboxamide and $\mathrm{N}^{1}$-methyl-4-pyridone-3-carboxamide were decreased by chronic ethanol administration, thus explaining the increased urinary excretion of MNA (Shibata, 1990). Previously, Forchette \& Patterson (1983) demonstrated this latter effect and suggested that it may be due to an increase in TP activity by chronic ethanol treatment. In view of the absence of evidence for such an increase in most other studies, the inhibition of MNA oxidases demonstrated by Shibata (1990) is the more likely explanation. Although MNA excretion is considered as an expression or index of increased dietary intake of nicotinic acid or tryptophan, the above studies on MNA excretion show that this is not always the case and illustrate the importance of determining activities of enzymes involved in its metabolism before implicating nutritional factors.

The serotonin pathway. In the earlier studies of the chronic effects of ethanol on 5-HT concentration, synthesis and/or turnover, decreases, increases or no changes have all been reported (for references, see Badawy et al. 1979). Differences in these earlier results can be attributed to differences in animal species tested, method of assessment of 5-HT turnover, and the use of sucrose as a control treatment; one which, as discussed earlier (p. 133), can itself modulate 5-HT metabolism and is therefore unsuitable in alcohol-5-HT studies (see also Badawy et al. 1980b). Subsequent studies have also produced contradictory results (for review and references, see LeMarquand et al. 1994b). However, overall, more studies have shown chronic ethanol administration to increase rat brain 5-HT concentration, synthesis and/or turnover rates. The most robust observations in relation to these changes have been the increases in plasma, brain and/or cerebrospinal fluid (CSF) Trp concentration, and the inhibition of liver TP activity discussed earlier (p. 134). It may therefore be concluded that, in general, chronic ethanol administration enhances cerebral 5-HT synthesis and turnover by elevating brain Trp concentration by increasing circulating Trp availability to the brain. The mechanism of this latter increase most likely involves inhibition of liver TP activity, evidence for which was obtained in a variety of experiments demonstrating reversal of the chronic ethanol-induced increase in 5-HT synthesis and turnover by reversal of the TP inhibition after acute administration of the regenerators of hepatic $\mathrm{NAD}^{+}\left(\mathrm{P}^{+}\right)$phenazine methosulfate, pyruvate, fructose and methylene blue (Badawy et al. 1979) and the opiate antagonist naloxone (Badawy et al. 1981), and prevention of the 5-HT changes by abolition of the ethanol-induced inhibition of TP activity by simultaneous chronic administration of the ADH inhibitor pyrazole (Punjani et al. 1979).

Other aspects of 5-HT metabolism have also been studied, but less comprehensively, namely melatonin-related metabolism and 5-hydroxytryptophol formation. Moss et al. (1986) found that chronic ethanol treatment (by 6-9 daily doses by mouth) decreased pineal melatonin concentration, whereas subsequent withdrawal exerted no effect. This decrease began after $1 \mathrm{~d}$ of ethanol treatment and could thus be considered an acute or a semi-acute effect, which may be due to inhibition of serotonin- $N$-acetyltransferase activity, an observation made by Creighton \& Rudeen (1988) after acute ethanol administration. As regards 5-hydroxytryptophol formation in rat brain, as described earlier (p. 133), the increase observed after acute ethanol administration in two discrete areas could not be demonstrated after chronic treatment (Beck et al. 1986). Many of the earlier studies on this aspect of 5-HT metabolism in animal brains have been equivocal (for references, see Beck et al. 1986), almost certainly because of the low cerebral $\mathrm{ADH}$ activity. 


\section{Withdrawal effects}

As is the case with the chronic effects, no studies of the decarboxylation and transamination pathways have been reported during acute alcohol withdrawal in experimental animals.

The hepatic kynurenine-nicotinic acid pathway. Studies on TP activity during alcohol withdrawal have been performed almost exclusively in our laboratory. In our earlier studies with chronic ethanol administration in drinking water, we found (Badawy \& Evans, 1972, 1973, 1975a) that, upon withdrawal of the $10 \%$ (v/v) aqueous ethanol drinking solution, TP activity remained inhibited for $3 \mathrm{~d}$, returning to normal levels $2 \mathrm{~d}$ later, then rose to a maximum (approximately $2 \cdot 5$-fold) $8 \mathrm{~d}$ after withdrawal, before a final return to basal levels on day 10 . The TP enhancement during withdrawal was of the hormonal type (Badawy \& Evans, 1973, 1975a) and mirrored changes in serum corticosterone concentration (Badawy et al. 1980a), thus suggesting a glucocorticoid induction mechanism. However, using the liquid diet procedure, we (Bano et al. 1996; Oretti et al. 2000) found that enhancement of TP activity during withdrawal exhibits a much faster time-course (reaching a 3-fold maximum at about 8-10 h), which correlated closely with that of the intensity of the AWS, and that the increase in TP activity was of the cofactor type, associated with increased haem saturation. In these latter two studies (Bano et al. 1996; Oretti et al. 2000), we also showed a parallel increase in the gene expression of TP, further implicating hormonal induction as the mechanism of increase in enzyme activity. However, this latter notion cannot be reconciled with the observed cofactortype activation. A possible explanation is provided by a recent study (Ren \& Correia, 2000) showing that haem regulation of TP may be exerted primarily at the transcriptional level. The above rapid increase in TP activity after withdrawal of ethanol-containing liquid diets explains the activation observed by Branchey \& Lieber (1982), discussed earlier (p. 134), which was considered by these authors to be an effect of chronic treatment, but which is more likely to be an effect of withdrawal, as rats were tested at least $3 \mathrm{~h}$ after removal of the liquid diet.

Induction of liver TP activity during alcohol withdrawal may be an important feature of the AWS. Thus, we found (Oretti et al. 2000) that the time-course of induction of TP activity and gene expression mirrored very closely that of the behavioural features of the AWS. Earlier, we observed (Oretti et al. 1996) that prevention of this induction by the translational inhibitor cycloheximide prevented the development of the AWS. The hyperexcitability and other behavioural features of the AWS are thought to involve activation of the excitatory NMDA-type of glutamate receptors as a response to cessation of long-term alcohol consumption (Gonzales, 1990; Lovinger, 1995), and it is known that, apart from glutamate itself, the Trp metabolite quinolinic acid is perhaps the most powerful indirect-acting (via glutamate) endogenous agonist of NMDA receptors (Stone, 1993). The possible involvement of quinolinic acid in the AWS has already been hypothesized (Morgan, 1991) and induction of liver TP activity during alcohol withdrawal may provide the link, since, as stated earlier, at least $50 \%$ of brain quinolinate is of peripheral origin (Heyes \& Morrison, 1997) and elevation of brain levels of this excitotoxin could therefore occur following liver TP enhancement. This hypothesis awaits critical appraisal.

The serotonin pathway. Here again, the contradictory literature (for review and references, see LeMarquand et al. 1994b) can be explained by differences in methods and routes of previous ethanol administration, speed of onset of the withdrawal syndrome, animal species and/or strain tested, method of assessment of 5-HT synthesis and/or turnover, and the choice of the time-interval(s) during withdrawal at which experiments have been performed. In general, how- 
ever, more studies than not have shown that 5-HT synthesis and turnover are decreased during alcohol withdrawal in association with decreases in precursor Trp availability to and within the brain, thus supporting our own investigations (Badawy et al. 1980a,c). Evidence implicating liver TP enhancement as the most likely mechanism was obtained from experiments (Badawy et al. 1980a) showing that the withdrawal-induced changes in brain 5-HT and Trp are abolished by preventing the TP enhancement by administration of nicotinamide.

From the above accounts, it is clear that acute and chronic ethanol administration and subsequent withdrawal in experimental animals, particularly rats, exert major effects on Trp metabolism and disposition and that the effects on brain Trp, and hence 5-HT, metabolism are mediated by changes in circulating Trp availability to the brain caused mainly by changes in liver TP activity. In the next section, it will be shown that liver TP may also be the target of ethanol in man.

\section{The effects of alcohol on tryptophan metabolism in man}

For obvious reasons, in studies with human subjects, conclusions regarding specific organ metabolic changes are derived from indirect measurements of parameters in blood, serum, plasma, urine and/or CSF. However, since the liver is the major organ of Trp degradation, which determines circulating Trp concentration, changes in the latter reflect largely those in hepatic handling through the kynurenine-nicotinic acid pathway, and, together with albumin binding and kynurenine determinations, serum Trp changes can be used to assess the TP status in human liver. Likewise, since serum Trp : CAA is the most accurate predictor of brain Trp and, hence, 5-HT, changes, this ratio can be used to assess the brain 5-HT biosynthetic status. The 5-HT degradative (or turnover) status, on the other hand, can be assessed through determination of the major 5-HT metabolite 5-HIAA in CSF for brain, or in urine for total body, 5-HT metabolism. Finally, urinary kynurenine metabolite levels reflect activity of the hepatic (and, under conditions of immune activation, also the extrahepatic) kynurenine-nicotinic acid pathway and the flux of Trp through it.

\section{Acute effects}

For obvious ethical reasons, the acute effects of ethanol are studied mainly in healthy volunteers, but also to a certain extent in non-abstinent, and rarely in abstinent, alcoholic patients.

The hepatic kynurenine-nicotinic acid pathway. A moderate oral dose of ethanol $(0 \cdot 8 \mathrm{~g} / \mathrm{kg}$ body weight) given to healthy fasting male volunteers causes a significant decrease in serum Trp concentration (Badawy et al. 1995). This decrease involves both free and total Trp in relatively similar proportions, i.e. without changes in Trp binding. This is a typical feature of liver TP enhancement. It may therefore be concluded that in man, as in rats, acute ethanol intake enhances liver TP activity. We have also observed decreases in serum Trp concentration in male subjects in the fed state, and also in female volunteers (CJ Morgan and AA-B Badawy, unpublished results). The mechanism of enhancement of TP activity in fasting subjects is unlikely to involve the substrate Trp, because serum Trp concentration was not increased, nor hormonal induction, since serum cortisol concentration was not altered by ethanol, except for the changes due to the diurnal cycle, which were also observed in the control experiment. Cofactor activation 
is therefore the most likely mechanism. As stated earlier in the corresponding section in animals (see p. 132), TP activation in starved rats is of the cofactor type, mediated by increased haem synthesis, and a similar mechanism is therefore also likely in man.

Previously, three studies in non-alcoholic subjects examined the acute effects of alcohol (whisky or pure ethanol) on circulating Trp concentration. In one (Pietraszek et al. 1991), no changes in blood Trp concentration were observed at $45 \mathrm{~min}$ after drinking whisky (though the zero-time value was not reported), whereas in the other two studies (Siegel et al. 1964; Eriksson et al. 1983), a decrease was demonstrated. In these latter two studies, sampling was performed at time-intervals after drinking longer than 45 min, suggesting that it was too early after alcohol consumption for Pietraszek et al. (1991) to demonstrate a significant decrease, given also our own more detailed ( $3 \mathrm{~h}$ ) time-course study (Badawy et al. 1995). It may therefore be concluded that, generally, acute ethanol consumption by healthy non-alcoholic subjects decreases circulating Trp concentration by enhancing liver TP activity.

The effects of acute ethanol intake on circulating Trp concentration were also studied in alcoholic patients. In the study by Siegel et al. (1964) of a group of alcoholics, acute ethanol intake did not lower plasma Trp concentration. It should be noted that fasting plasma Trp concentration was already lower in the alcoholic, compared with the control, group in this study (a finding which will be discussed further later; see p. 141). In a study of three non-abstinent alcoholic subjects, we found (CJ Morgan, AA-B Badawy and R Thomas, unpublished results) that acute ethanol consumption also fails to lower serum Trp concentration. One possible explanation of these findings is that chronic alcohol consumption inhibits liver TP activity (see later; p. 139), thus preventing activation by an acute dose.

The serotonin pathway. As stated earlier (p. 131), serum Trp : CAA is the most accurate predictor of brain Trp changes and, hence, 5-HT synthesis. Very few studies have examined directly or indirectly Trp availability to the brain as assessed with the above ratio after acute ethanol consumption. In our earlier study in normal male volunteers (Badawy et al. 1995), we found that free and total Trp : CAA were decreased by acute ethanol consumption, thus almost certainly predicting an ethanol-induced inhibition of brain 5-HT synthesis. This decrease in the ratio was found to be due to the decrease in Trp concentration described above, rather than to a rise in the sum of concentrations of its five competitors. This acute ethanol-induced decrease in brain 5-HT provides a possible explanation of alcohol-induced dysphoria, depression and aggression, at least in susceptible individuals (Badawy et al. 1995), and may also provide a mechanism for loss of control in general and also in relation to romance and sexual behaviour after alcohol consumption (Badawy, 2000). In the other study in which concentrations of the five Trp competitors were determined (Eriksson et al. 1983), it was calculated that, $1 \mathrm{~h}$ after consumption of whisky, total Trp : CAA was decreased from a mean control value of $0 \cdot 095$ to a value of $0 \cdot 067$. In one study in which CSF Trp concentration was assessed in normal subjects, a decrease has also been demonstrated (Beck et al. 1983). It may therefore be concluded that acute ethanol intake by healthy subjects decreases circulating Trp availability to the brain, thus almost certainly leading to inhibition of cerebral 5-HT synthesis.

Zarcone et al. (1980) administered a dose of $3 \mathrm{~g}$ ethanol/kg body weight (over several h beginning at noon) to alcoholic subjects who were abstinent for at least $30 \mathrm{~d}$ and observed at 07.00 hours on the following morning a significant decrease (of about $30 \%$ ) in CSF 5-HIAA concentration. This finding provides further evidence that acute ethanol intake decreases brain 5-HT synthesis.

The acute effects of ethanol on the whole-body 5-HT status have been assessed by measurement of the urinary excretion of 5-HIAA. Davis et al. (1967) showed that ethanol decreases 
urinary 5-HIAA concentration, but increases that of the corresponding alcohol, 5-hydroxytryptophol. As stated earlier, this represents an ethanol-induced shift in 5-HT metabolism from the major oxidative, to the minor reductive, pathway, the mechanism(s) of which are possibly 2fold: (1) competition from acetaldehyde with 5-hydroxyindol-3-ylacetaldehyde for the AlDH reaction leading to 5-HIAA formation (Lahti \& Majchrowicz, 1969); (2) an increase in NADH : $\mathrm{NAD}^{+}$favouring reduction of the latter aldehyde to 5-hydroxytryptophol (Feldstein et al. 1964). Since little ethanol metabolism occurs in the brain to cause a significant increase in cerebral acetaldehyde concentration or $\mathrm{NADH}: \mathrm{NAD}^{+}$, the increased urinary excretion of 5-hydroxytryptophol is almost certainly the result of peripheral (mainly hepatic) ethanol metabolism. A major recent application of the above shift in 5-HT metabolism has been the use of urinary 5hydroxytryptophol : 5-HIAA as a very sensitive marker of current and recent alcohol consumption (Helander et al. 1994; see also Bendtsen et al. 1998), which also provides an accurate and objective indicator of relapse after detoxification.

The decarboxylation and transamination pathways. Although urinary excretion of the tryptamine metabolite IAA both under basal conditions (Thomson \& McMillen, 1987) and after an oral Trp load (Friedman et al. 1984) was found to be normal in recently detoxified alcoholics (see later; p. 142), the effects of acute alcohol intake on this metabolite or on the transamination product IPA have not been studied.

\section{Chronic effects}

The hepatic kynurenine-nicotinic acid pathway. Only four published studies have assessed indirectly the effects of chronic alcohol intake on this pathway in non-abstinent alcoholics. In the first of these studies, Siegel et al. (1964) showed that, whereas serum Trp concentration was decreased in control subjects following acute ethanol loading, no decrease was observed in chronic alcoholics, thus implying a possible inhibition of liver TP activity, as discussed above. Evidence for a disturbance of this pathway by chronic alcohol consumption was subsequently provided by the demonstration (Walsh et al. 1966) that, within $24 \mathrm{~h}$ of cessation of alcohol consumption, chronic alcoholic subjects excreted decreased amounts of kynurenine metabolites in urine following an oral Trp load. These authors interpreted this as indicative of pyridoxine deficiency induced by the increased requirement for $\mathrm{NAD}^{+}$, which, in their opinion, leads to an increased incorporation of tryptophan into the nicotinic acid synthetic pathway. However, there is no evidence for such an increase, nor for excessive intake of Trp by alcoholics. On the contrary, it is because of poor nutritional intake of Trp and niacin (coupled with a potential inhibition of liver TP activity) that alcoholics in certain parts of Southern Africa develop pellagra, which also occurs in patients with the carcinoid syndrome because of diversion of Trp away from the kynurenine pathway (for a discussion and references, see Badawy \& Evans, 1974). A more likely explanation of the above decrease in urinary kynurenine metabolites excretion is therefore that of possible inhibition of liver TP activity by chronic alcohol consumption, as is the case in rats. In the third study, Friedman et al. (1988) reported that serum kynurenine concentration (an index of hepatic Trp oxidation) in alcoholic subjects after an oral Trp load was lower during the first week of abstinence than 4 weeks later, suggesting that liver TP activity may be decreased (or normal, because no control values were given) soon after detoxification. These latter authors also found that, whereas serum kynurenine levels after a Trp load remained higher in subjects who continued to be abstinent, they became decreased again in subjects who 
relapsed into drinking, thus suggesting that resumption of drinking decreases Trp oxidation. As stated earlier (p. 138) under the acute effects, we observed in a few non-abstinent alcoholics that acute ethanol intake did not decrease serum Trp concentration and interpreted this as suggesting a liver TP inhibition. Serum Trp concentration was not determined in the above two studies with Trp loading, but was in a study by Hjorth et al. (1981), who observed a decrease after administration of a Trp load to a group of alcoholics within $24 \mathrm{~h}$ of admission for detoxification. This finding will be discussed later (p. 141) in relation to withdrawal. Taken together, these preliminary data suggest that, in man, as in rats, chronic alcohol consumption inhibits liver TP activity; however, further more detailed studies are clearly required to ascertain this interpretation.

The serotonin pathway. This pathway has received greater attention over the years. However, as is the case with experimental animal studies, many of the studies with human subjects also suffer from interpretational problems related to methodological differences (for review and references, see LeMarquand et al. 1994a), and, in particular, whether the observed changes could be attributed to chronic alcohol intake or subsequent withdrawal, as, with only two exceptions, almost all studies examined patients in the abstinence phase, yet attributed the findings generally to chronic alcoholism. Even in studies performed in drinking alcoholics, interpretation of results is difficult, because it would not be easy to dissociate any acute effects for which tolerance does not develop with repeated consumption from those induced by long-term alcohol intake. In attempting to separate findings which could be attributed to chronic ethanol consumption, only two studies were identified, which examined parameters while the subjects were still intoxicated or within a day of the last alcohol intake. Thus, urinary excretion of 5-HIAA was found (Walsh et al. 1966) to be normal in alcoholics after an oral Trp load given within $24 \mathrm{~h}$ of cessation of alcohol consumption, and CSF 5-HIAA concentration was measured in intoxicated chronic alcoholics within $4 \mathrm{~h}$ of drinking and was found (Borg et al. 1985) not to be decreased, but to correlate with blood-ethanol concentration. These latter authors concluded that brain 5-HT activity is likely to be increased during chronic long-term alcohol consumption. This is consistent with the changes in kynurenine levels, described above, reflecting decreased hepatic Trp degradation by chronic alcohol consumption, thus potentially leading to diversion of Trp metabolism towards 5-HT synthesis. The 5-HT status in chronic alcoholics will be further discussed later (p. 141) in the section dealing with the withdrawal effects.

The decarboxylation and transamination pathways. No studies of the chronic effects of alcohol on the transamination pathway have been performed. However, two studies have examined the decarboxylation pathway. Kissin et al. (1973) demonstrated an elevation of urinary tryptamine excretion in alcoholic subjects during repeated intoxication over a 7-10 d period, a finding previously reported by the same group (Schenker et al. 1966), which was suggested to be due to increased tryptamine turnover, though no measurement of the tryptamine metabolite IAA was made.

\section{Withdrawal effects}

The hepatic kynurenine-nicotinic acid pathway. Friedman et al. (1988) observed higher serum kynurenine levels after an oral Trp load in 3-month abstinent subjects, compared with 
levels during the first week of abstinence or in subjects who later relapsed into drinking, thus suggesting that liver TP activity may be higher in abstinent alcoholics. The question arises as to whether a high TP activity is a trait feature of alcoholism or one induced by alcohol withdrawal. The answer (which will be discussed further later) is to compare changes during the immediate withdrawal phase with those in stable longer-term abstinence. No studies other than that by Friedman et al. (1988) have been performed in longer-term abstinent patients. Some studies, however, have been performed in shorter-term abstinence $(<3$ months, usually 2-3 weeks or earlier). Thus serum Trp concentration was found to be lower in recently abstinent alcoholics, compared with controls (Siegel et al. 1964; Branchey et al. 1984; Diehl et al. 1986), and in 1-d abstinent alcoholics, compared with subsequent days up to day 42 (BuydensBranchey et al. 1989). As stated above, Hjorth et al. (1981) observed a lower serum Trp concentration following Trp loading in alcoholics during the first $24 \mathrm{~h}$ of withdrawal, but not in other patients examined at subsequent time intervals. Buydens-Branchey et al. (1988) earlier proposed that liver TP activity may be higher in 3-d, compared with 1-month, abstinent alcoholics, as suggested from differences in urinary kynurenine excretion following an oral Trp load. However, plasma Trp measurements by these authors did not reveal time differences, a finding at odds with their proposal. In a study by Thomson \& McMillen (1987), urinary excretion of another kynurenine metabolite, anthranilic acid, was not significantly different between controls and recently abstinent alcoholics. Thus urinary metabolite excretion data do not always reflect specific organ metabolic changes. Serum Trp concentration was determined in one study (Hjorth et al. 1981) before and following an oral Trp load in a small group of alcoholic patients within $24 \mathrm{~h}$ after admission for detoxification, and was found to be lower than in controls at 4-6 h after, but not before, the Trp load. No significant differences from controls were, however, noted by these authors in groups of abstinent alcoholics.

In our own study of Trp disposition in acute alcohol withdrawal, we (Badawy et al. 1998) found that both free and total serum Trp concentrations were dramatically increased in male alcoholic patients within the $24 \mathrm{~h}$ preceding the appearance of the AWS, compared with control subjects. As the onset of this syndrome varied between 2 and $5 \mathrm{~d}$, it is clear that daily measurements are needed to establish the Trp-metabolic status of alcohol-dependent patients during acute withdrawal. We also found that serum cortisol levels were also dramatically elevated on the eve of the AWS, and it is therefore possible that this may herald TP induction during withdrawal, the effect of which would be to lower serum Trp concentration, which may explain the low levels reported by Buydens-Branchey et al. (1989) discussed above. Further detailed timecourse studies should therefore establish more clearly the Trp metabolic status during acute alcohol withdrawal. The above dramatic increases in circulating Trp concentration and availability to the brain (Badawy et al. 1998) also raise the possibility that cerebral levels of the NMDA-receptor agonist quinolinate may be elevated during the AWS; further studies are needed to examine this possibility.

The serotonin pathway. Hardly any studies have addressed the question of the effect of acute alcohol withdrawal on brain 5-HT. When CSF 5-HIAA concentration was measured in subjects $1 \mathrm{~d}$ (Borg et al. 1985) or 1-2 d (Ballenger et al. 1979) after admission for detoxification, no differences from controls were observed. The demonstration by Buydens-Branchey et al. (1989) of a lower plasma Trp concentration and Trp : CAA after $1 \mathrm{~d}$, compared with subsequent days, of withdrawal suggests that the 5-HT pathway may be inhibited in acute alcohol withdrawal. However, as stated earlier, a detailed time-course study of the effects of acute withdrawal is needed. 
Studies on whole-body 5-HT turnover have also been performed through measurement of urinary 5-HIAA excretion. When the latter was determined following an oral Trp load in alcoholics during the first $24 \mathrm{~h}$ after cessation of alcohol consumption, no differences from controls were observed (Walsh et al. 1966). Studies at subsequent days after withdrawal have been inconsistent, with decreases having been detected by some investigators (Olson et al. (1960) on day 5, and Thomson \& McMillen (1987) on day 17), but not by others (Murphy et al. 1962; Payne et al. 1974; Akhter et al. 1978). No clear-cut conclusions could therefore be reached from these urinary data, which in any case do not reflect cerebral 5-HT metabolism.

The decarboxylation and transamination pathways. No studies of the transamination pathway in acute alcohol withdrawal have been reported. However, tryptamine excretion in urine was shown by Kissin et al. (1973) to return to normal levels during withdrawal following the elevation observed during experimental chronic alcoholization of alcohol-dependent subjects. Serum levels of the tryptamine metabolite IAA were measured by Friedman et al. (1984) in alcoholics following detoxification and were also found not to be different from those in control subjects.

From the above accounts, it is clear that acute and chronic alcohol consumption and subsequent withdrawal exert major effects on Trp metabolism and disposition in both man and experimental animals (summarized in Table 1), but unlike animal studies, much more work is needed with human subjects to delineate the changes induced by chronic consumption and the acute phase of the subsequent withdrawal period. Changes observed after longer withdrawal periods will be considered later (p. 145).

\section{The tryptophan metabolic status of experimental animal models of alcoholism}

In addition to the animal studies described earlier, the Trp-metabolic status of alcohol-preferring animal species and/or lines has also been studied, though not exhaustively. That animal species show marked differences in their preference to alcohol in a free-choice paradigm has been known since the pioneering work of Arvola \& Forsander (1961). However, in the past 2-3

Table 1. Effects of alcohol on tryptophan metabolism and disposition in man and experimental animals during acute (A) and chronic (C) alcohol consumption and withdrawal (W)

\begin{tabular}{|c|c|c|c|c|c|c|}
\hline \multirow[b]{2}{*}{ Parameter } & \multicolumn{3}{|c|}{ Animals } & \multicolumn{3}{|c|}{ Man } \\
\hline & A & $\mathrm{C}$ & W & A & C & W \\
\hline \multicolumn{7}{|l|}{ Liver TP: } \\
\hline Activity & $\uparrow$ & $\downarrow$ & $\uparrow$ & $\uparrow$ & $\downarrow$ & $\uparrow$ \\
\hline Mechanism & Substrate & $\mathrm{NAD}(\mathrm{P}) \mathrm{H}$ & Hormonal & Cofactor & $\mathrm{NAD}(\mathrm{P}) \mathrm{H} ?$ & $?$ \\
\hline Free serum Trp concentration & $\uparrow, \downarrow$ & $\uparrow$ & $\downarrow$ & $\downarrow$ & ? & $?$ \\
\hline Total serum Trp concentration &,$- \downarrow$ & $\uparrow$ & $\downarrow$ & $\downarrow$ & $?$ & $\downarrow$ \\
\hline Trp binding & $\downarrow,-$ & - & - & - & $?$ & $?$ \\
\hline Trp : CAA & $?$ & $?$ & $?$ & $\downarrow$ & $?$ & $\downarrow$ \\
\hline Brain Trp concentration & $\uparrow, \downarrow$ & $\uparrow$ & $\downarrow$ & $\downarrow ?$ & $?$ & $\downarrow ?$ \\
\hline Brain 5-HT concentration & $\uparrow, \downarrow$ & $\uparrow$ & $\downarrow$ & $\downarrow ?$ & $?$ & $\downarrow ?$ \\
\hline Brain 5-HIAA concentration & $\uparrow, \downarrow$ & $\uparrow$ & $\downarrow$ & $\downarrow ?$ & $?$ & $\downarrow$ ? \\
\hline CSF 5-HIAA concentration & $?$ & $?$ & $?$ & $?$ & $?$ & $?$ \\
\hline Urinary 5-HIAA concentration & $?$ & $?$ & $?$ & $\downarrow$ & $?$ & (?) \\
\hline
\end{tabular}

TP, tryptophan pyrrolase; Trp, tryptophan; CAA, competing amino acids, namely valine, leucine, isoleucine, phenylalanine and tyrosine; 5-HT, 5-hydroxytryptamine; 5-HIAA, 5-hydroxyindol-3-ylacetic acid; CSF, cerebrospinal fluid; $\uparrow$, increase; $\downarrow$, decrease; ?, not determined; $\downarrow$ ?, and NAD(P)H?, strong possibility of effect, even though not determined; (?), controversial or equivocal findings; - - , unchanged. 
decades, it has become clear that strains and/or lines genetically bred for preference to alcohol form important experimental animal models of alcoholism in which to study potential biological (including genetic) determinants of preference and hence possibly dependence. In the case of the mouse, the C57BL/6J strain has been shown to be the most alcohol-preferring of all mouse strains (McLearn \& Rogers, 1959; Yoshimoto et al. 1985; Yoshimoto \& Komura, 1987), whereas, in the rat, a number of lines are known to prefer alcohol to water, namely the Finnish AA (Kiianmaa et al. 1991), the Chilean UChB (Mardones \& Segovia-Requelme, 1983), the Maudsley Reactive MRA (Satinder, 1972; Adams et al. 1991), the Fawn-Hooded (Rezvani et al. 1990; Overstreet et al. 1993), the Indiana $\mathrm{P}$ (Li et al. 1987) and the Sardinian sP (Colombo, 1997), in comparison with their non-preferring counterparts (namely ANA, UchA, Maudsley Non-Reactive NMRA, Sprague-Dawley, and Wistar NP and sNP respectively).

An interesting aspect of Trp metabolism in relation to alcohol preference is the low central 5 -HT concentration in a number of the above animal models, including the C57BL/6J mouse (Badawy \& Evans, 1976c; Yoshimoto et al. 1985; Yoshimoto \& Komura, 1987), Fawn-Hooded (Rezvani et al. 1990), P (Murphy et al. 1987), the Maudsley Reactive (Broadhurst, 1975) and sP (Devoto et al. 1998) rat lines. This deficiency may be important in view of the role of 5-HT in alcohol-consummatory behaviour (for review, see Sellers et al. 1992). The 5-HT status of the Chilean UchB rat line is unknown. The AA rat line may, however, be the exception, as it has been shown not to be 5-HT-deficient (Korpi et al. 1988).

The mechanism(s) of this 5-HT decrease has been examined in some detail only in three of these models, namely the C57BL/6J mouse and the P and the sP rat lines. In the P rat, the 5-HT deficiency may simply be due to a lower density of serotonergic fibres in cerebral cortex (Zhou et al. 1991). The C57BL/6J mouse, which has been known for some time to have less 5-HT in the brain than the non-preferring CBA/Ca (Badawy \& Evans, 1976c) and various other (Yoshimoto et al. 1985; Yoshimoto \& Komura, 1987) strains possesses a liver TP twice as active as that of the CBA/Ca strain (Badawy \& Evans, 1976c), a finding which we subsequently confirmed in another study (Badawy et al. 1989), in which we also showed that this higher activity, which is associated with a higher circulating corticosterone concentration, is almost certainly responsible for the decrease in circulating Trp availability to the brain, which leads to the lower rates of 5-HT synthesis and turnover in this strain. Trp metabolism and disposition have also been studied in the Sardinian alcohol-preferring sP rat by Bano et al. (1998), who found that, in association with an increased concentration of serum corticosterone and enhanced gene expression of liver TP, activity of this enzyme in sP rats was 38-58\% higher than in SNP rats. The concentrations of free serum, total serum and brain Trp were significantly, if moderately (10-19\%) lower in sP, compared with sNP, rats. These small decreases, however, were not associated with lower levels of brain 5-HT or 5-HIAA in sP, $v$. sNP, rats. On the contrary, both 5-HT and 5-HIAA concentrations were significantly higher in sP rats, suggesting increased turnover of Trp in sP rats. In addition to this potential mechanism, the possibility cannot be ruled out that the 5-HT deficiency demonstrated in cortex by Devoto et al. (1998) may be associated with lower Trp concentration in this brain structure. As will be discussed later (p. 145), of all the above animal models of alcohol preference, the C57BL/6J mouse may be the most suitable for studying the Trp and 5-HT metabolic status in human alcoholism.

\section{The tryptophan metabolic status in human alcoholism}

As stated earlier (p. 141), the great majority of studies of Trp and 5-HT metabolism in alcoholism have been performed in subjects who have been abstinent for periods varying from $5 \mathrm{~d}$ 
to $>3$ months. The minimum time needed for the chronic and/or acute withdrawal changes in Trp and 5-HT metabolism to disappear has not been studied in man. In the rat, it is clear from the accounts given earlier in the present review that at least 7-11 $\mathrm{d}$ after withdrawal would be such a minimum period. It would, however, be unwise to extrapolate this to the situation in man, given that some subjects experience 'late' withdrawal and clinically some behavioural disorders secondary to alcohol dependence, which may have biochemical correlates; for example depression can take up to 4 weeks after withdrawal to resolve. There is also the possibility that pathological changes associated with long-term alcohol dependence, for example liver cirrhosis, may exert permanent effects on Trp disposition (for example, see Rössle et al. 1986; Bergeron et al. 1989). Accordingly, the Trp metabolic status of human alcoholism should best be studied in long-term abstinence and in subjects not afflicted with overt organ damage, or, preferably, in offspring of adults with a family history of alcoholism before their exposure to alcohol. Very few such studies have been performed and the following is an account of these.

The kynurenine-nicotinic acid pathway. The observation by Buydens-Branchey et al. (1988) of a lower urinary kynurenine excretion after an oral Trp load in 1-month, compared with 3-d, abstinent subjects is difficult to interpret for at least two reasons: (1) these two time intervals are not directly comparable, particularly in the absence of an appropriate control group, because of possible changes during the acute withdrawal phase; (2) the urinary kynurenine data did not correspond to the plasma Trp data, which did not show differences between $3 \mathrm{~d}$ and 1 month. More clear-cut data were obtained by Friedman et al. (1988), who showed that serum kynurenine concentration following an oral Trp load was higher in 1-month abstinent alcoholic subjects, than during the first week of detoxification, thus suggesting that liver TP activity may be higher a month after abstinence. These latter authors also showed that kynurenine formation from Trp was impaired in alcoholics who relapsed into drinking after the first 3 months of abstinence, compared with those who remained abstinent, thus suggesting that resumption of alcohol consumption is associated with liver TP inhibition. It may therefore be suggested that liver TP activity in abstinent alcoholics is enhanced, though further studies comparing alcoholics with controls are needed to establish this conclusion more firmly. A higher liver TP activity in abstinent alcoholics could be of aetiological importance as a potential trait marker and/or determinant of alcohol dependence, or at least of a potential 5-HT deficiency in alcoholism.

In marked contrast to the above studies on circulating Trp concentration in abstinent alcoholic subjects, Farren \& Dinan (1996a) reported that 4-month abstinent alcoholics have a higher serum Trp concentration than controls. The data by these latter authors are unusual in that the mean control serum Trp concentration $(33 \mu \mathrm{M})$ is much lower than normal values in the literature quoted in the present review (50-85 $\mu \mathrm{M})$. In addition, the method used to determine tryptophan (auto-analyser) does not require another method referred to by the authors. Farren $\&$ Dinan (1996a) also found that serum cortisol concentration was also elevated in alcoholics, yet this apparently was not associated with a lower serum Trp concentration, as would be expected with hormonal induction of TP. No further explanations of the differences between the data of Farren \& Dinan (1996a) and earlier studies can be offered.

The serotonin pathway. This pathway has received much greater attention. Thus, the majority of the urinary 5-HIAA studies referred to above were performed at various times after abstinence. For example, urinary 5-HIAA concentration was found to be decreased after 5 (Olson et al. 1960) or 17 (Thomson \& McMillen, 1987) d, but not at $7 \mathrm{~d}$ (Murphy et al. 1962) 
or other time intervals after withdrawal (Payne et al. 1974; Akhter et al. 1978). Clearly these findings are contradictory and the situation is compounded by the fact that urinary 5-HIAA excretion does not reflect the central 5-HT status. However, it is clear from the study by Thomson \& McMillen (1987) that, generally, there appears to be a total body deficiency in the 5-HT pathway in (at least 17-d) abstinent alcoholics. Studies of CSF 5-HIAA concentration have also led to equally contradictory conclusions regarding the central 5-HT status of alcoholics (for references, see LeMarquand et al. 1994a). Studies demonstrating lower than normal levels of CSF 5-HIAA were performed on 2-week to 3-month abstinent alcoholics (see LeMarquand et al. 1994a and references cited therein). With the longest abstinence durations, CSF 5-HIAA concentration was shown to be decreased at 1-2 (Ballenger et al. 1979) and 3 (Borg et al. 1985) months. Taken together, these results suggest that longer-term abstinence is associated with a defective central 5-HT turnover.

Decreased 5-HT turnover could be due to inhibition of degradation or of synthesis. Decreased degradation can be ruled out, since a lower MAO activity should result in elevated, rather than decreased, 5-HT levels, which is contrary to the above observations. Also, there is no suggestion that MAO-A (the form of the enzyme mainly responsible for 5-HT breakdown) is abnormal in alcoholism. On the contrary, MAO-B activity is frequently reported to be lower in platelets of alcoholics, though this is a controversial finding (see Parsian et al. 1994). Decreased 5-HT synthesis is therefore the more likely explanation of the above CSF 5-HIAA data. That this is so is strongly suggested from circulating Trp concentration and Trp : CAA determinations. Thus, a lower circulating Trp concentration in alcoholics has been a consistent finding of many studies (Siegel et al. 1964; Hjorth et al. 1981; Branchey et al. 1984; Diehl et al. 1986; Buydens-Branchey et al. 1989). In the study by Siegel et al. (1964), however, no information on the duration of abstinence of the alcoholic subjects was given, whereas in the other four studies, measurements were made at times after abstinence varying between 7 and $12 \mathrm{~d}$ in one study and up to $42 \mathrm{~d}$ in another. In the study by Buydens-Branchey et al. (1989), although serum Trp concentration rose gradually (from a low value immediately following the last alcohol intake) with increasing length of abstinence, it was still lower than the value from a control group tested by these authors in their earlier study (Branchey et al. 1984). Decreases in Trp : CAA were also reported in these latter two studies (Branchey et al. 1984; BuydensBranchey et al. 1989), thus suggesting that Trp availability to the brain is impaired in abstinent alcoholics, almost certainly as a result of accelerated hepatic degradation of the amino acid, as suggested from the increase in serum kynurenine concentration discussed above (Friedman et al. 1988) and the decrease in serum Trp reported by Hjorth et al. (1981) following an oral Trp load. Buydens-Branchey et al. (1989) further suggested that the decrease in Trp : CAA in alcoholic subjects, which becomes more pronounced in the presence of depression and/or aggression (Branchey et al. 1984), is associated with these two behavioural disorders only in early-onset alcoholics (those classed under Type II by Cloninger (1987)). Taken together, these studies strongly suggest that brain 5-HT synthesis and turnover are defective in short- to medium-term (up to 3 months) abstinent alcoholics, directly as a result of a decrease in circulating Trp availability to the brain, almost certainly caused by a higher liver TP activity. To establish if this is also the case in long-term abstinence, further studies are needed.

If the above 5-HT defect involves this TP-mediated mechanism, then, of all alcohol-preferring animal models with a central 5-HT deficiency, the C57BL/6J mouse strain may be the nearest and therefore most suitable model for studying the human 5-HT deficiency of alcoholism, in view of the similar mechanism established in this mouse strain.

The question also arises whether a potential 5-HT deficiency in alcoholism is a predisposing biological determinant of alcohol dependence. It is tempting to speculate, from the data by 
Friedman et al. (1988), that alcoholics may self-medicate for their 5-HT deficiency by liver TP inhibition. An attempt was made by us to establish if the 5-HT deficiency in recent abstinence is present in all, or in a subgroup(s) of, alcoholic patients. In a group of recently detoxified alcoholic patients, we (Morgan et al. 1995) found that free or total serum Trp concentration was not different at 1, 3 or 8 weeks after detoxification, nor apparently different from control values. However, when this group of sixty patients was divided into those with positive ( $n$ 33), and those with negative ( $n$ 27), family history of alcoholism, the former group showed a significantly lower total serum Trp concentration. This family-history-related deficiency was also observed in female, as well as male, patients. These observations, however preliminary and therefore in need of replication, strongly suggest that at least a subgroup of alcohol-dependent patients may be 5-HT-deficient, possibly through genetic predisposition. Serum Trp concentration was also examined by Farren \& Dinan (1996b) in relation to family history of alcoholism and was found to be unrelated to it. These authors, as in their earlier study (Farren \& Dinan, $1996 a$ ), also found that compared with controls, abstinent alcoholics had a higher serum Trp concentration, despite having impaired 5-HT function.

The question of the 5-HT status in relation to family history of alcoholism is of further interest in the context of alcoholism typologies and personality characteristics. Thus, BuydensBranchey et al. (1989) suggested that the decrease in Trp availability to the brain (expressed as a low Trp : CAA) correlated with the presence of depressive and aggressive tendencies only in alcoholic subjects with early-onset alcoholism, i.e. Type II in the classification by Cloninger (1987). It should, however, be pointed out that this decreased ratio was demonstrated only $1 \mathrm{~d}$ after cessation of alcohol intake and may thus only represent a potential effect of acute withdrawal, rather than being a stable trait marker, which requires demonstration at longer periods of abstinence. In fact, the earlier work by the same group (Branchey et al. 1984) showed clearly that, irrespective of the presence of depression or aggression and in the absence of typing, 7-12-d abstinent alcoholics in general had lower Trp : CAA than controls. A central 5-HT deficiency, however, has been demonstrated in a non-human primate model of alcoholism by the group of Linnoila (Higley \& Bennett, 1999). Thus, primates with low CSF 5-HIAA concentration exhibit behaviours characteristic of Type II alcoholism, especially deficits in impulse control, for example spontaneous risky and reinforcing behaviours, impaired social competence, social alienation and unrestrained and violent aggression (for review and references, see Higley \& Bennett, 1999). It is of interest that evidence linking antisocial alcoholism to the serotonin $5 \mathrm{HT}_{1 \mathrm{~B}}$ receptor gene (Lappalainen et al. 1998) and of impulsive aggression to a mutation in the gene encoding for MAO-A (the form of MAO responsible for 5-HT degradation) (Brunner et al. 1993) have been reported. 5-HT function has also been examined in subjects at high risk for alcohol dependence. With CSF 5-HIAA concentration measurements, impairment was demonstrated (Rosenthal et al. 1980; Linnoila et al. 1989), whereas in 5-HT receptor binding studies, the results have been controversial (Suranyi-Cadotte et al. 1989; Rausch et al. 1991; Ernouf et al. 1993). Taken together, the results obtained so far in this regard strongly suggest the need for further studies on the 5-HT metabolic and functional status of alcoholic patients in relation to personality and genetic characteristics.

\section{General conclusions and comments}

The present review has shown that Trp metabolism and disposition in man and experimental animals are greatly influenced by acute and chronic alcohol intake or administration and during subsequent withdrawal, and that most of the changes observed are caused by modulation of 
liver TP activity. Although the maximum changes in Trp disposition and in 5-HT synthesis observed as a consequence seem to be modest (i.e. about $25 \%$ ), maintenance of such changes over periods of weeks, months or even years, together with the fact that the liver continually degrades its free Trp several times every $h$ and the possibility that these metabolic changes could even be greater in susceptible individuals, all strongly suggest that modulation of the Trp and 5-HT status by alcohol could exert important physiological, behavioural and psychological effects in subjects exposed to it. More studies are required in human subjects to establish more accurately the Trp and 5-HT status during alcohol dependence and the subsequent acute withdrawal phase. Studies in longer-term abstinence are also needed to establish this status in relation to predisposition to dependence and to the associated psychological and behavioural disturbances, which may also be important determinants of the dependence mechanism through negative reinforcement. Establishing the 5-HT status in relation to personality characteristics and alcoholism typologies will also make an important contribution towards identifying the biopsychosocial determinants of dependence, biological (including genetic) vulnerability factors, and patient characteristics, which should lead to more effective screening and detection of subjects at risk of becoming dependent on alcohol, targeting patients for specific pharmacological interventions and improving the practice of detoxification.

\section{References}

Adams N, Shihabi, ZK \& Blizard DA (1991) Ethanol preference in the Harrington derivation of the Maudsley Reactive and Non-Reactive strains. Alcoholism: Clinical and Experimental Research 15, 170-174.

Akhter MI, Clark PMS, Kricka LJ \& Nicholson G (1978) Urinary metabolites of tryptophan, serotonin, and norepinephrine in alcoholics. Journal of Studies on Alcohol 39, 833-841.

Arvola A \& Forsander O (1961) Comparison between water and alcohol consumption in six animal species in freechoice experiments. Nature (London) 191, 819-820.

Asaad MM, Barry H III, Clarke DE \& Dixit BN (1974) Effect of ethanol on the oxidative metabolism of tryptamine by rat liver homogenate. British Journal of Pharmacology 50, 277-282.

Badawy AA-B (1977) Minireview - The functions and regulation of tryptophan pyrrolase. Life Sciences 21, $755-767$.

Badawy AA-B (1978) The metabolism of alcohol. Clinics in Endocrinology and Metabolism 7, 247-271.

Badawy AA-B (1979) Biochemical Review: Central role of tryptophan pyrrolase in haem metabolism. Biochemical Society Transactions 7, 575-583.

Badawy AA-B (1984) The functions and regulation of tryptophan pyrrolase. In Progress in Tryptophan and Serotonin Research, pp. 641-650 [HG Schlossberger, W Kochen, B Linzen and H Steinhart, editors]. Berlin: Water de Gruyter \& Co.

Badawy AA-B (1988) Effects of pregnancy on tryptophan metabolism and disposition in the rat. Biochemical Journal 255, 369-372.

Badawy AA-B (2000) Serotonin: the stuff of romance - a light hearted commentary. The Biochemist 22, 15-17.

Badawy AA-B \& Evans M (1972) The effects of ethanol on the activity of rat liver tryptophan pyrrolase. Biochemical Society Transactions 1, 193-195.

Badawy AA-B \& Evans M (1973) Tryptophan pyrrolase in ethanol administration and withdrawal. Advances in Experimental Medicine and Biology 35, 105-123.

Badawy AA-B \& Evans M (1974) Alcohol and tryptophan metabolism: a review. Journal of Alcoholism 9, 97-116.

Badawy AA-B \& Evans M (1975a) The effects of ethanol on tryptophan pyrrolase activity and their comparison with those of phenobarbitone and morphine. Advances in Experimental Medicine and Biology 59, 229-251.

Badawy AA-B \& Evans M (1975b) The regulation of rat liver tryptophan pyrrolase by its cofactor haem - experiments with haematin and 5-aminolaevulinate and comparison with the substrate and hormonal mechanisms. Biochemical Journal 150, 511-520.

Badawy AA-B \& Evans M (1976a) The regulation of rat liver tryptophan pyrrolase activity by reduced nicotinamideadenine dinucleotide (phosphate) - experiments with glucose and nicotinamide. Biochemical Journal 156, 381-390.

Badawy AA-B \& Evans M (1976b) Animal liver tryptophan pyrrolases - absence of apoenzyme and of hormonal induction mechanism from species sensitive to tryptophan toxicity. Biochemical Journal 158, 79-88.

Badawy AA-B \& Evans M (1976c) The role of free serum tryptophan in the biphasic effect of acute ethanol administration on the concentrations of rat brain tryptophan, 5-hydroxytryptamine and 5-hydroxyindol-3-ylacetic acid. Biochemical Journal 160, 315-324. 
Badawy AA-B \& Evans M (1979) Further evidence against inhibition of synthesis of rat liver tryptophan pyrrolase by chronic ethanol administration. British Journal on Alcohol and Alcoholism 14, 59-64.

Badawy AA-B \& Morgan CJ (1982) Tryptophan and tryptophan pyrrolase in haem regulation - the role of lipolysis and direct displacement of serum-protein-bound tryptophan in the opposite effects of administration of endotoxin, morphine, palmitate, salicylate and theophylline on rat liver 5-aminolaevulinate synthase activity and the haem saturation of tryptophan pyrrolase. Biochemical Journal 206, 451-460.

Badawy AA-B, Morgan CJ \& Davis NR (1986) Tryptophan pyrrolase and the regulation of mammalian hepatic haem biosynthesis. In Porphyrins and Porphyrias, pp. 69-81 [Y Nordman, editor]. London: John Libby Eurotext Ltd.

Badawy AAB, Morgan CJ, Lane J, Dhaliwal K \& Bradley DM (1989) Liver tryptophan pyrrolase: a major determinant of the lower brain 5-hydroxytryptamine concentration in alcohol-preferring C57BL mice. Biochemical Journal 264, 597-599.

Badawy AA-B, Morgan CJ, Lovett JWT, Bradley DM \& Thomas R (1995) Decrease in circulating tryptophan availability to the brain after acute ethanol consumption by normal volunteers: implications for alcohol-induced aggressive behaviour and depression. Pharmacopsychiatry 28, Suppl. 2, 93-97.

Badawy AA-B, Punjani, NF \& Evans, M (1979) Enhancement of rat brain tryptophan metabolism by chronic ethanol administration and possible involvement of decreased liver tryptophan pyrrolase activity. Biochemical Journal 178, 575-580.

Badawy AA-B, Punjani NF, Evans CM \& Evans M (1980a) Inhibition of rat brain tryptophan metabolism by ethanol withdrawal and possible involvement of the enhanced liver tryptophan pyrrolase activity. Biochemical Journal 192, 449-455.

Badawy AA-B, Punjani NF \& Evans M (1980b) Unsuitability of control sucrose or glucose in studies of the effects of chronic ethanol administration on brain 5-hydroxytryptamine metabolism. Journal of Pharmacological Methods $\mathbf{3}$, $167-171$.

Badawy AA-B, Punjani NF \& Evans M (1980c) The effects of ethanol on rat liver and brain tryptophan metabolism. Substance and Alcohol Actions/Misuse 1, 507-515.

Badawy AA-B, Punjani NF \& Evans M (1981) Reversal by naloxone of the effects of chronic administration of drugs of dependence on rat liver and brain tryptophan metabolism. British Journal of Pharmacology 74, 489-494.

Badawy AA-B, Rommelspacher H, Morgan CJ, Bradley DM, Bonner A, Ehlert A, Blum S \& Spies CD (1998) Tryptophan metabolism in alcoholism: tryptophan but not excitatory amino acid availability to the brain is increased before the appearance of the alcohol-withdrawal syndrome in men. Alcohol and Alcoholism 34, 616-625.

Ballenger JC, Goodwin FK, Major LF \& Brown GL (1979) Alcohol and central serotonin metabolism in man. Archives of General Psychiatry 36, 224-227.

Bano S, Morgan CJ, Badawy AA-B, Colombo G, Buckland PR, McGuffin P, Fadda F \& Gessa GL (1998) Tryptophan metabolism in male Sardinian alcohol-preferring (sP) and-non-preferring (sNP) rats. Alcohol and Alcoholism 33, 220-225.

Bano S, Oretti RG, Morgan CJ, Badawy AA-B, Buckland P \& McGuffin P (1996) Effects of chronic administration and subsequent withdrawal of ethanol-containing liquid diet on rat liver tryptophan pyrrolase and tryptophan metabolism. Alcohol and Alcoholism 31, 205-215.

Beck O, Borg S \& Sedvall G (1983) Tryptophan levels in human cerebrospinal fluid after acute and chronic ethanol consumption. Drug and Alcohol Dependence 12, 217-222.

Beck B, Eriksson CJP, Kiianmaa K \& Lundman A (1986) 5-hydroxyindoleacetic acid and 5-hydroxytryptophol levels in rat brain: effects of ethanol, pyrazole, cyanamide and disulfiram treatment. Drug and Alcohol Dependence 16, 303-308.

Bender DA (1982) Biochemistry of tryptophan in health and disease. Molecular Aspects of Medicine 6, 101-197.

Bender DA \& Totoe L (1984) Inhibition of tryptophan metabolism by oestrogens in the rat: a factor in the aetiology of pellagra. British Journal of Nutrition 51, 219-224.

Bendtsen P, Jones AW \& Helander A (1998) Urinary excretion of methanol and 5-hydroxytryptophol as biochemical markers of recent drinking in the hangover state. Alcohol and Alcoholism 33, 431-438.

Bengtsson F (1999) Brain tryptophan/serotonin perturbations in metabolic encephalopathy and the hazards involved in the use of psychoactive drugs. Advances in Experimental Medicine and Biology 467, 139-154.

Bergeron M, Reader TA, Layrargues GM \& Butterworth RF (1989) Monoamines and metabolites in autopsied brain tissue from cirrhotic patients with hepatic encephalopathy. Neurochemical Research 14, 853-859.

Billker O, Lindo V, Panico M, Etienne AE, Paxton T, Dell A, Rogers M, Sinden RE \& Morris HR (1998) Identification of xanthurenic acid as the putative inducer of malaria development in the mosquito. Nature 392, 289-292.

Borg S, Kvande H, Liljeberg P, Mossberg D \& Valverius P (1985) 5-Hydroxyindoleacetic acid in cerebrospinal fluid in alcoholic patients under different clinical conditions. Alcohol 2, 415-418.

Braidman IP \& Rose DP (1971) Effects of sex hormones on three glucocorticoid-inducible enzymes concerned with amino acid metabolism in rat liver. Endocrinology 89, 1250-1255.

Branchey L, Branchey M, Shaw S \& Lieber CS (1984) Depression, suicide, and aggression in alcoholics and their relationship to plasma amino acids. Psychiatry Research 12, 219-226.

Branchey L \& Lieber CS (1982) Activation of tryptophan pyrrolase after chronic alcohol administration. Substance and Alcohol Actions/Misuse 2, 225-229.

Broadhurst P (1975) The Maudsley reactive and non-reactive strains of rats. Behavioural Genetics 5, $299-319$. 
Brodie BB, Butler WM Jr, Honing MG, Maickel RP \& Maling HM (1961) Alcohol-induced triglyceride deposition in liver through derangement of fat transport. American Journal of Clinical Nutrition 9, 432-435.

Brunner HG, Nelen M, Breakefield XO, Ropers HH \& van Oost BA (1993) Abnormal behavior associated with a point mutation in the structural gene for monoamine oxidase A. Science 262, 578-580.

Buydens-Branchey L, Branchey M, Worner TM, Zucker D, Aramsombatdee E \& Lieber CS (1988) Increase in tryptophan oxygenase activity in alcoholic patients. Alcoholism: Clinical and Experimental Research 12, $163-167$.

Buydens-Branchey L, Branchey MH, Noumair D \& Lieber CS (1989) Age of alcoholism onset II. Relationship to susceptibility to serotonin precursor availability. Archives of General Psychiatry 46, 231-236.

Carlsson A \& Lindqvist M (1978) Dependence of 5-HT and catecholamine synthesis on concentrations of precursor amino acids in rat brain. Naunyn-Schmiedeberg's Archives of Pharmacology 303, 157-164.

Cebrian ME, Albores A, Connelly JC \& Bridges JW (1988) Assessment of arsenic effects on cytosolic heme status using tryptophan pyrrolase as an index. Journal of Biochemical Toxicology 3, 77-86.

Cho-Chung YS \& Pitot HC (1967) Feedback control of rat liver tryptophan pyrrolase. Journal of Biological Chemistry 242, 1192-1198.

Cloninger CR (1987) Neurogenetic adaptive mechanisms in alcoholism. Science 236, 410-416.

Colombo G (1997) Ethanol drinking behaviour in Sardinian alcohol-preferring rats. Alcohol and Alcoholism 32, 443-453.

Creighton JA \& Rudeen PK (1988) Effects of acute ethanol administration on nocturnal pineal serotonin N-acetyltransferase activity. Life Sciences 43, 2007-2014.

Curzon G (1979) Relationship between plasma, CSF and brain tryptophan. Journal of Neural Transmission 15, Suppl., 81-92.

Curzon G \& Knott PJ (1974) Effects on plasma and brain tryptophan in the rat of drugs and hormones that influence the concentration of unesterified fatty acids in the plasma. British Journal of Pharmacology 50, 197-204.

Davis VE, Brown H, Huff JA \& Cashaw JL (1967) The alteration of serotonin metabolism to 5-hydroxytryptophol by ethanol ingestion in man. Journal of Laboratory and Clinical Medicine 69, 132-140.

DeLap L \& Feigelson P (1978) Effect of cycloheximide on the induction of tryptophan oxygenase mRNA by hydrocortisone in vivo. Biochemical and Biophysical Research Communications 82, 142-149.

Devoto P, Colombo G, Stefanini E \& Gessa GL (1998) Serotonin is reduced in the frontal cortex of Sardinian ethanolpreferring rats. Alcohol and Alcoholism 33, 226-229.

Diehl AME, Mitchell MC, Herlong HF, Potter JJ, Wacker L \& Mezey E (1986) Changes in plasma amino acids during sobriety in alcoholic patients with and without liver disease. American Journal of Clinical Nutrition 44, 453-460.

Drummond GS, Galbraith RA, Sardana MK \& Kappas A (1987) Reduction of the $\mathrm{C}_{2}$ and $\mathrm{C}_{4}$ vinyl groups of Sn-protoporphyrin to form Sn-mesoporphyrin markedly enhances the ability of the metalloporphyrin to inhibit in vivo heme catabolism. Archives of Biochemistry and Biophysics 255, 64-74.

El-Sokkary GH, Reiter RJ, Tan D-X, Kim SJ \& Cabrera J (1999) Inhibitory effect of melatonin on products of lipid peroxidation resulting from chronic ethanol administration. Alcohol and Alcoholism 34, 842-850.

Eriksson T, Magnusson T, Carlsson A, Hagman M \& Jagenburg R (1983) Decrease in plasma amino acids in man after an acute dose of ethanol. Journal of Studies on Alcohol 44, 215-221.

Ernouf D, Campagnon P, Lothion P, Narcisse G, Bénard JY \& Daoust M (1993) Platelet ${ }^{3} \mathrm{H}$ 5-HT uptake in descendants from alcoholic patients: a potential risk factor for alcohol dependence. Life Sciences 52, 989-995.

Evans M \& Badawy AA-B (1977) The mechanism of inhibition of rat liver tryptophan pyrrolase activity by chronic ethanol administration. Biochemical Society Transactions 5, 1037-1038.

Farren CK \& Dinan TG (1996a) Elevated tryptophan levels in post-withdrawal alcoholics. Acta Psychiatrica Scandinavica 94, 465-470.

Farren CK \& Dinan TG (1996b) High serum tryptophan associated with evidence for diminished central serotonin function in abstinent alcoholics. Human Psychopharmacology 11, 511-516.

Feldstein A, Hoagland H, Wong K \& Freeman H (1964) Biogenic amines, biogenic aldehydes and alcohol. Quarterly Journal of Studies on Alcohol 25, 218-225.

Fernstrom JD \& Wurtman RJ (1971) Brain serotonin content: physiological dependence on plasma tryptophan levels. Science 173, 149-152.

Forchette CA \& Patterson JI (1983) Effects of chronic ethanol feeding on the metabolism of tryptophan and nicotinamide in rats. Journal of Nutrition 113, 1936-1945.

Friedman MJ, Krstulović, AM, Colin H, Guiochon G \& Pajer K (1984) Serum indole-3-acetic acid in control subjects and newly abstinent alcoholics after an oral loading with L-tryptophan: a preliminary study using liquid chromatography with amperometric detection. Analytical Biochemistry 142, 480-486.

Friedman MJ, Krstulović AM, Severinghaus JM \& Brown SJ (1988) Altered conversion of tryptophan to kynurenine in newly abstinent alcoholics. Biological Psychiatry 23, 89-93.

Gal EM (1974) Tryptophan 5-hydroxylase: function and control. Advances in Biochemical Psychopharmacology 11, $1-11$.

Gonzales RA (1990) NMDA receptors excite alcohol research. Trends in Pharmacological Sciences 11, 137-139.

Greengard O \& Feigelson P (1961) The activation and induction of rat liver tryptophan pyrrolase in vivo by its substrate. Journal of Biological Chemistry 236, 158-161.

Hawkins R \& Kalant H (1972) The metabolism of ethanol and its metabolic effects. Pharmacological Reviews 24, $67-157$. 
Helander A, Beck O \& Borg S (1994) The use of 5-hydroxytryptophol as an alcohol intake marker. Alcohol and Alcoholism 29, Suppl. 2, 497-502.

Heyes MP (1996) The kynurenine pathway and neurological disease: therapeutic strategies. Advances in Experimental Medicine and Biology 398, 125-129.

Heyes MP \& Morrison PF (1997). Quantification of local de novo synthesis versus blood contributions to quinolinic acid concentrations in brain and systemic tissues. Journal of Neurochemistry 68, 280-288.

Heyes MP, Saito K, Chen CY, Proescholdt MG, Nowak TS Jr, Li J, Beagles KE, Proescholdt MA, Zito MA, Kawa K \& Markey SP (1997) Species heterogeneity between gerbils and rats: quinolinate production by microglia and astrocytes and accumulations in response to ischaemic brain injury and systemic immune activation. Journal of Neurochemistry 69, 1519-1529.

Higley JD \& Bennett AJ (1999) Central nervous system serotonin and personality as variables contributing to excessive alcohol consumption in non-human primates. Alcohol and Alcoholism 34, 402-418.

Hjorth M, Bille M \& Smith DF (1981) Serum tryptophan levels in alcoholics. Drug and Alcohol Dependence 7, 157-161.

Kaliman PA \& Manandhar SP (1990) The effects of inhibitors of transcription and translation on basal and haeminduced tryptophan-2, 3-dioxygenase activity in rat liver. Biomedical Science 1, 165-170.

Kiianmaa K, Stenius K \& Sinclair JD (1991) Determinants of alcohol preference in the AA and ANA rat lines selected for differential ethanol intake. Alcohol and Alcoholism 26, Suppl. 1, 115-120.

Kissin B, Gross MM \& Schutz I (1973) Correlation of urinary biogenic amines with sleep stages in chronic alcoholization and withdrawal. Advances in Experimental Medicine and Biology 35, 281-289.

Knox WE \& Auerbach VH (1955) The hormonal control of tryptophan peroxidase in the rat. Journal of Biological Chemistry 214, 307-313.

Korpi ER, Sinclair JD, Kadeinen P, Viitamaa T, Helluvuo K \& Kiianmaa K (1988) Brain regional and adrenal monoamine concentrations and behavioral responses to stress in alcohol-preferring AA and alcohol-avoiding ANA rats. Alcohol 5, 417-425.

Kotake Y \& Murakami E (1971) A possible diabetogenic role for tryptophan metabolites and effects of xanthurenic acid on insulin. American Journal of Clinical Nutrition 24, 812-829.

Lahti RA \& Majchrowicz E (1969) Acetaldehyde - an inhibitor of the enzymatic oxidation of 5-hydroxyindole acetaldehyde. Biochemical Pharmacology 18, 535-538.

Lapin IP \& Politi V (1994) Antiethanol effects of indol-3-ylpyruvic acid in mice. Alcohol and Alcoholism 29, $265-268$.

Lappalainen J, Long JC, Eggert M, Ozaki N, Robin RW, Brown GL, Naukkarinen H, Virkkunen M, Linnoila M \& Goldman D (1998) Linkage of antisocial alcoholism to the serotonin 5-HT1B receptor gene in 2 populations. Archives of General Psychiatry 55, 989-994.

LeMarquand D, Pihl RO \& Benkelfat C (1994a) Serotonin and alcohol intake, abuse, and dependence: clinical evidence. Biological Psychiatry 36, 326-337.

LeMarquand D, Pihl RO \& Benkelfat C (1994b) Serotonin and alcohol intake, abuse, and dependence: findings of animal studies. Biological Psychiatry 36, 395-421.

Li T-K, Lumeng L, McBride WJ \& Murphy J (1987) Rodent lines selected for factors affecting alcohol consumption. Alcohol and Alcoholism 22, Suppl. 1, 91-96.

Linnoila M, De Jong J \& Virkkunen M (1989) Family history of alcoholism in violent offenders and impulsive fire setters. Archives of General Psychiatry 46, 613-616.

Lovinger DM (1995) Ethanol and the NMDA receptor: implications for intoxication, tolerance, dependence and alcoholic brain damage. In Acamprosate in Relapse Prevention in Alcoholism, pp. 1-26 [M. Soyka, editor]. Berlin: Springer.

McLearn, GE \& Rogers DA (1959) Differences in alcohol preference among inbred strains of mice. Quarterly Journal of Studies on Alcohol 20, 691-695.

Mardones J \& Segovia-Requelme N (1983) Thirty two years of selection of rats by ethanol preference: UchA and UchB strains. Neurobehavioral Toxicology and Teratology 5, 171-178.

Meek JL \& Neff NH (1972) Tryptophan 5-hydroxylase: approximation of half-life and rate of axonal transport. Journal of Neurochemistry 19, 1519-1525.

Mehler AH, McDaniel EG \& Hundley JM (1958) Changes in the enzymatic composition of liver: (ii) influence of hormones on picolinic carboxylase and tryptophan peroxidase. Journal of Biological Chemistry 232, 331-335.

Morgan CJ, Badawy AA-B, Den Dulk A, Verbanck P \& Pelc I (1995) Lower serum tryptophan concentrations in alcoholics with positive family history. Alcohol and Alcoholism 30, 554.

Morgan PF (1991) Is quinolinic acid an endogenous excitotoxin in alcohol withdrawal? Medical Hypotheses 36, $118-121$.

Mørland J (1974) Effects of chronic ethanol treatment on tryptophan oxygenase, tyrosine aminotransferase and general protein metabolism in intact and perfused rat liver. Biochemical Pharmacology 23, 21-35.

Mørland J, Stowell L \& Gjerde H (1985) Ethanol increases rat liver tryptophan oxygenase: evidence for corticosterone mediation. Alcohol 2, 255-259.

Moss HB, Tamarkin L, Majchrowicz E, Martin PR \& Linnoila M (1986) Pineal function during ethanol intoxication, dependence and withdrawal. Life Sciences 39, 2209-2214.

Mousseau DD (1993) Tryptamine: a metabolite of tryptophan implicated in various neuropsychiatric disorders. Metabolic Brain Diseases 8, 1-44. 
Murphy GE, Guze SB \& King LJ (1962) Urinary excretion of 5-HIAA in chronic alcoholism. Journal of the American Medical Association 182, 565.

Murphy JM, McBride WJ, Lumeng L \& Li T-K (1987) Contents of monoamines in four brain regions of alcohol-preferring (P) and -non-preferring (NP) lines of rats. Pharmacology, Biochemistry and Behavior 26, 389-392.

Nakamura T, Niimi S, Nawa K, Noda C, Ichihara A, Takagi Y, Anai M \& Sakaki Y (1987) Multihormonal regulation of transcription of tryptophan 2,3-dioxygenase gene in primary cultures of adult rat hepatocytes with special reference to the presence of a transcriptional protein mediating the action of glucocorticoids. Journal of Biological Chemistry 262, 727-733.

Nakamura T, Shinno H \& Ichihara A (1980) Insulin and glucagon as a new regulator system for tryptophan-oxygenase activity demonstrated in primary cultured rat hepatocytes. Journal of Biological Chemistry 255, 7533-7535.

Noda C, Nakamura T \& Ichihara A (1983) Alpha-adrenergic regulation of enzymes of amino acid metabolism in primary cultures of adult rat hepatocytes. Journal of Biological Chemistry 258, 1520-1525.

Oldendorf WH \& Szabo J (1976) Amino acid assignment to one of three blood-brain barrier amino acid carriers. American Journal of Physiology 230, 94-98.

Olson RE, Gursey D \& Vester JW (1960) Evidence for a defect in tryptophan metabolism in chronic alcoholism. New England Journal of Medicine 263, 1169-1174.

Oretti R, Bano S, Morgan CJ, Badawy AA-B, Bonner A, Buckland P \& McGuffin P (1996) Prevention by cycloheximide of the audiogenic seizures and tryptophan metabolic disturbances of ethanol withdrawal in rats. Alcohol and Alcoholism 31, 243-247.

Oretti RG, Bano S, Azani MO, Badawy AA-B, Morgan CJ, McGuffin P \& Buckland PR (2000) Rat liver tryptophan pyrrolase activity and gene expression during alcohol withdrawal. Alcohol and Alcoholism 35, 427-434.

Overstreet DH, Kampov-Polevoy AB, Rezvani AH, Murrelle L, Halikas J \& Janowsky DS (1993) Saccharin intake predicts ethanol intake in genetically heterogeneous rats as well as different rat strains. Alcoholism: Clinical and Experimental Research 17, 366-369.

Ozaki Y, Edelstein MP \& Duch DS (1988) Induction of indoleamine 2,3-dioxygenase: a mechanism of the antitumor activity of interferon $\gamma$. Proceedings of the National Academy of Sciences USA 85, 1242-1246.

Parsian A, Suarez BK, Tabakoff B, Hoffman P, Ovchinnikova L, Fisher L \& Cloninger CR (1994) Monoamine oxidases and alcoholism: studies in unrelated alcoholics, normal controls and alcoholic families. Alcohol and Alcoholism 29, Suppl. 2, 45-49.

Payne IR, Lu GHY \& Meyer K (1974) Relationship of dietary tryptophan and niacin to tryptophan metabolism in alcoholics and non-alcoholics. American Journal of Clinical Nutrition 27, 572-579.

Pfefferkorn ER, Rebhun S \& Eckel M (1986) Characterization of an indoleamine 2,3-dioxygenase induced by gamma interferon in cultured human fibroblasts. Journal of Interferon Research 6, 267-279.

Pietraszek MH, Urano T, Sumioshi K, Serizawa K, Takahashi S, Takada Y \& Takada A (1991) Alcohol-induced depression: involvement of serotonin. Alcohol and Alcoholism 26, 155-159.

Politi V, D’Alessio S, Di Stazio G \& De Luca G (1996) Antioxidant properties of indole-3-pyruvic acid. Advances in Experimental Medicine and Biology 398, 291-298.

Politi V, De Luca G, Gallai V, Puca O \& Comin M (1999) Clinical experience with the use of indole-3-pyruvic acid. Advances in Experimental Medicine and Biology 467, 227-232.

Punjani NF, Badawy AA-B \& Evans M (1979) Prevention by pyrazole of the effects of chronic ethanol administration on the redox state of the hepatic nicotinamide-adenine dinucleotide (phosphate) couples and on liver and brain tryptophan metabolism in the rat. Biochemical Journal 184, 165-168.

Rausch JL, Monteiro MG \& Schuckit MA (1991) Platelet serotonin uptake in men with family history of alcoholism. Neuropsychopharmacology 4, 83-86.

Reiter RJ (1996) The indoleamine melatonin as a free radical scavenger, electron donor and antioxidant. Advances in Experimental Medicine and Biology 398, 307-313.

Ren S \& Correia MA (2000) Heme: a regulator of rat hepatic tryptophan 2,3-dioxygenase? Archives of Biochemistry and Biophysics 377, 195-203.

Rezvani AH, Overstreet DH \& Janowsky DS (1990) Genetic serotonin deficiency and alcohol preference in the Fawn Hooded rats. Alcohol and Alcoholism 25, 573-575.

Rommelspacher H, Damm H, Strauss S \& Schmidt G (1984) Ethanol induces an increase of harman in brain and urine of rats. Naunyn-Schmiedeberg's Archives of Pharmacology 327, 107-113.

Rosenthal NE, Davenport Y, Cowdry RW, Webster MH \& Goodwyn FK (1980) Monoamine metabolites in cerebrospinal fluid of depressive subgroups. Psychiatry Research 2, 113-119.

Rössle M, Herz R, Klein B \& Gerok W (1986) Tryptophan-metabolismus bei Lebererkrankungen: Eine pharmakokinetische und enzymatische Untersuchung (Tryptophan metabolism in liver disease: a pharmacokinetic and enzymatic study). Klinische Wochenschrift 64, 590-594.

Rouach H, Ribiere C, Nordmann J \& Nordmann R (1980) Acute ethanol effects on rat liver tryptophan oxygenase and tyrosine aminotransferase. Pharmacology, Biochemistry and Behavior 13, Suppl. 1, 139-143.

Salter M, Knowles RG \& Pogson CI (1986) Quantification of the importance of individual steps in the control of aromatic amino acid metabolism. Biochemical Journal 234, 635-647.

Sardesai VM \& Provido HS (1972) The effect of ethyl alcohol on rat liver tryptophan oxygenase. Life Sciences 11, 1023-1028. 
Satinder KP (1972) Behavior-genetic-dependent self-selection of alcohol in rats. Journal of Comparative Physiology and Psychology 80, 422-434.

Schenker J, Kissin B, Maynard LS \& Schenker AC (1966) The effect of ethanol on urinary tryptamine excretion. In Biochemical Factors in Alcoholism, pp. 39-52 [R Marchel, editor]. Oxford: Pergamon Press.

Schimke RT, Sweeney EW \& Berlin CM (1965a) The roles of synthesis and degradation in the control of rat liver tryptophan pyrrolase. Journal of Biological Chemistry 240, 322-331.

Schimke RT, Sweeney EW \& Berlin CM (1965b) Studies on the stability in vivo and in vitro of rat liver tryptophan pyrrolase. Journal of Biological Chemistry 240, 4609-4620.

Schutz G, Beato M \& Feigelson P (1973) Messenger-RNA for hepatic tryptophan oxygenase: its partial purification, its translation into a heterologous cell-free system and its control by glucocorticoid hormones. Proceedings of the National Academy of Sciences USA 70, 1218-1221.

Sellers EM, Higgins GA \& Sobell MB (1992) 5-HT and alcohol abuse. Trends in Pharmacological Sciences 13, 69-75.

Shibata K (1990) Effects of ethanol feeding and growth on the tryptophan-niacin metabolism in rats. Agricultural and Biological Chemistry 54, 2953-2959.

Siddiqui SM, Rao GS \& Pandya KP (1988) Depletion of liver regulatory heme in benzene exposed rats. Toxicology 48, $245-251$.

Sidransky H, Verney E, Latham P \& Schwartz A (1996) Effects of tryptophan related compounds on nuclear regulatory control. Advances in Experimental Medicine and Biology 398, 343-350.

Siegel FL, Roach MK \& Pomeroy LR (1964) Plasma amino acid patterns in alcoholism: the effects of ethanol loading. Proceedings of the National Academy of Sciences USA 51, 605-611.

Smith SA, Carr FPA \& Pogson CI (1980) The metabolism of L-tryptophan by isolated rat liver cells. Biochemical Journal 192, 673-686.

Spies CD, Rommelspacher H, Schnapper C, Müller C, Marks C, Berger G, Conrad C, Blum S, Specht M, Hanneman L, Striebel HW \& Schaffartzik W (1995) $\beta$-Carbolines in chronic alcoholics undergoing elective tumor resection. Alcoholism: Clinical and Experimental Research 19, 969-976.

Stone TW (1993) Neuropharmacology of quinolinic and kynurenic acids. Pharmacological Reviews 45, 309-385.

Stowell L, Stowell A \& Mørland J (1983) Increase in rat liver tryptophan oxygenase activity after acute ethanol treatment: dependence on feeding state and route of ethanol administration. Alcohol and Alcoholism 18, 119-127.

Suranyi-Cadotte B, Dongier M, Lafaille F \& Luthe L (1989) Platelets of alcoholics, and of subjects genetically at risk for alcoholism, share the same abnormality of imipramine binding sites. British Journal of Addiction 84, 437-445.

Taylor MW \& Feng G (1991) Relationship between interferon- $\gamma$, indoleamine 2,3-dioxygenase, and tryptophan catabolism. FASEB Journal 5, 2516-2522.

Thomson SM \& McMillen BA (1987) Test or decreased serotonin/tryptophan metabolite ratios in abstinent alcoholics. Alcohol 4, 1-5.

Wagner C (1964) Regulation of the tryptophan-nicotinic acid-DPN pathway in the rat. Biochemical and Biophysical Research Communications 17, 668-673.

Walsh MP, Howarth PJN \& Marks V (1966) Pyridoxine deficiency and tryptophan metabolism in chronic alcoholics. American Journal of Clinical Nutrition 19, 379-383.

Wodarz N, Wiesbeck GA, Rommelspacher H, Riederer P \& Böning J (1996) Excretion of B-carbolines harman and norharman in 24-hour urine of chronic alcoholics during withdrawal and controlled abstinence. Alcoholism: Clinical and Experimental Research 20, 706-710.

Yamazaki F, Kuroiwa T, Takikawa O \& Kido R (1985) Human indolylamine 2,3-dioxygenase: its tissue distribution, and characterization of the placental enzyme. Biochemical Journal 230, 635-638.

Yoshimoto K \& Komura S (1987) Reexamination of the relationship between alcohol preference and brain monoamines in inbred strains of mice including senescence-accelerated mice. Pharmacology, Biochemistry and Behavior 2, 317-322.

Yoshimoto K, Komura S, Kano A \& Mizohata K (1985) Alcohol preference and brain monoamines in five inbred strains of mice. IRCS Medical Science 13, 1192-1193.

Young SN \& Sourkes TL (1975) Tryptophan catabolism by tryptophan pyrrolase in rat liver. Journal of Biological Chemistry 250, 5009-5014.

Zarcone VP, Schreier L, Mitchell G, Orenberg E \& Barchas J (1980) Sleep variables, cyclic AMP and biogenic amine metabolites after one day of ethanol ingestion. Journal of Studies on Alcohol 41, 318-324.

Zhou FC, Bledsoe S, Lumeng L \& Li T-K (1991) Immunostained serotonergic fibers are decreased in selected brain regions of alcohol-preferring rats. Alcohol 8, 425-431. 